\title{
p57Kip2 regulates embryonic haematopoietic stem cell numbers by controlling the size of the sympathoadrenal progenitor pool
}

\section{Running Title: p57Kip2 deletion increases haematopoietic stem cell numbers}

Chrysa Kapeni ${ }^{1,2}$, Leslie Nitsche ${ }^{1}$, Alastair M. Kilpatrick ${ }^{1}$, Nicola K. Wilson ${ }^{2}$, Kankan Xia $^{2}$, Bahar Mirshekar-Syahkal ${ }^{2}$, Camille Malouf ${ }^{1}$, Berthold Göttgens ${ }^{2}$, Kristina Kirschner ${ }^{3,4}$, Simon R. Tomlinson ${ }^{1}$ and Katrin Ottersbach ${ }^{{ }^{*}}$

${ }^{1}$ Centre for Regenerative Medicine, University of Edinburgh, Edinburgh, EH16 4UU, UK

${ }^{2}$ Department of Haematology, Wellcome Trust-Medical Research Council Cambridge Stem Cell Institute,

University of Cambridge, Cambridge CB2 OAW, UK

${ }^{3}$ Institute of Cancer Sciences, University of Glasgow, Switchback Road, Glasgow, G61 1BD, UK

${ }^{4}$ CRUK Beatson Institute for Cancer Research, University of Glasgow, Switchback Road, Glasgow, G61 1BD, UK

\section{${ }^{*}$ Address for correspondence:}

Dr. Katrin Ottersbach

Centre for Regenerative Medicine

Institute for Regeneration and Repair

Edinburgh BioQuarter

5 Little France Drive

University of Edinburgh

Edinburgh EH16 4UU

UK

Tel. +441316519516

Fax: +44 1316519501

Email: katrin.ottersbach@ed.ac.uk

Web address: $\underline{\text { http://www.crm.ed.ac.uk/research/group/developmental-origins-blood-stem-cells- }}$ and-leukaemia 


\section{ABSTRACT}

33 Haematopoietic stem cells (HSCs) are of major clinical importance, and finding methods for their in 34 vitro generation is a prime research focus. We demonstrate that the cell cycle inhibitor p57Kip2/Cdkn1c limits HSC numbers by restricting the size of the sympathetic nervous system (SNS) and the amount of HSC-supportive catecholamines secreted by these cells, specifically in the aortagonads-mesonephros (AGM) region via $\beta 2$-adrenergic receptor signalling. This regulation occurs at the SNS progenitor level and is in contrast to the cell-intrinsic function of p57Kip2 in maintaining adult HSCs. Using single-cell RNA-Seq we dissect the differentiation pathway of neural crest cells into SNS cells in the AGM and reveal that they are able to take an alternative differentiation pathway, giving rise to a subset of mesenchymal cells expressing HSC-supportive factors. Neural crest cells thus appear to contribute to the AGM HSC niche via two different mechanisms: SNS-mediated catecholamine secretion and HSC-supportive mesenchymal cell production.

44

56 haematopoietic stem cells, aorta-gonads-mesonephros, p57Kip2/Cdkn1c, catecholamines,

57 sympathetic nervous system, neural crest, niche, single-cell RNA-Seq, mesenchyme 


\section{INTRODUCTION}

Haematopoietic stem cells (HSCs) with the ability to multilineage repopulate adult recipients are first detected at embryonic day (E) 10.5 in the aorta-gonads-mesonephros (AGM) region of the mouse embryo ${ }^{1,2}$. They are derived from specialised, haemogenic endothelial cells that can transdifferentiate into blood cells via a process termed endothelial-to-haematopoietic transition (recently reviewed in ${ }^{3-6}$ ). While this process is thought to occur in several embryonic tissues harbouring major vasculature, such as the head, yolk sac, placenta, vitelline and umbilical arteries, it is the AGM region where HSCS are first detected in robust numbers and where blood formation from endothelium has been observed by live imaging ${ }^{7-10}$. This suggests that the AGM has a unique environment particularly suited for promoting HSC formation, which is supported by its remarkable ability to expand HSCS and their precursors in aggregate cultures ${ }^{11}$.

Relatively little is currently known about the AGM haematopoietic niche and, specifically, the cell types and signals that regulate HSC generation, maintenance and egress ${ }^{12}$. A large panel of stromal cell lines has been derived from the AGM ${ }^{13-15}$, which have served as useful tools for the identification of HSC regulators ${ }^{16-19}$; however, the extent to which these represent the AGM microenvironment in vivo is unclear. Cells with characteristics of mesenchymal stromal cells have been detected in the AGM at the time of HSC generation, but their precise location and secretome are still unknown ${ }^{20}$. Tissues on the ventral side of the dorsal aorta, including the ventral mesenchyme and the gut, are known to provide HSC regulatory signals belonging to the Notch, Hedgehog and Bmp pathways ${ }^{17,21-26}$. HSC-supportive cytokines such as Scf and Thpo have also been detected in the sub-aortic mesenchyme ${ }^{25,27}$. In addition, our group has previously reported that cells of the sympathetic nervous system (SNS), which develops in the vicinity of the dorsal aorta at the time of HSC generation, promote HSC production through the secretion of catecholamines, under the control of the haematopoietic transcription factor Gata3 ${ }^{28}$.

Here, we report that the cell cycle regulator p57Kip2 (Cdkn1c) controls the size of the sympathoadrenal (SA) compartment and thus the amount of catecholamines produced in the AGM, which has a direct influence on HSC numbers. We had previously shown that deletion of p57Kip2 leads to an increase in HSCS at E12.5 ${ }^{29}$, which is in stark contrast to the essential role of p57Kip2 in adult HSC maintenance and quiescence ${ }^{30}$ and foetal liver (FL) HSC self-renewal ${ }^{31}$. We now provide further evidence that, unlike in adult HSC regulation, the effect of p57Kip2 on AGM HSCs is non-cell autonomous and occurs by regulating the proliferation of SA progenitors, hence providing another example of the differences in embryonic vs. adult HSC properties and regulation. We also further define the interaction between the developing haematopoietic and sympathetic nervous system and have generated a detailed characterisation of the emerging SA compartment via single-cell RNA-Seq. 
92

\section{RESULTS}

p57Kip2 deletion expands HSC numbers in the AGM and the early fetal liver.

We had previously reported an increase in repopulation activity of E12 p57Kip2-null AGMs and had suggested that this may be the result of a migration defect in HSCs that causes them to be retained in the $\mathrm{AGM}$ for longer before relocating to the $\mathrm{FL}^{29}$. We have now carried out further transplantation experiments, and have also detected a trend towards higher HSC numbers in the E11 p57Kip2-null AGM (Figure 1A), which, however, is not as marked as at E12 (Figure 1B). Furthermore, we observed significantly expanded HSC numbers in the early FL (Figure 1C), which argues against a migration defect and instead suggests that the expansion of the HSC pool in the AGM translates into higher numbers colonising the FL. This initial difference, however, disappears over time as HSC numbers in the FL rapidly increase from E12 (Figure 1D). Interestingly, p57Kip2 deletion had no effect on HSC numbers in the E11 and E12 placenta and yolk sac (Figure 1E-H), despite high expression in the placenta (Figure 1I), demonstrating that p57Kip2 is involved in HSC production specifically in the AGM.

\section{p57Kip2 is highly expressed in the sympathetic nervous system.}

To understand how p57Kip2 is involved in HSC production in the AGM, we analysed its expression pattern. Immunohistochemistry revealed weak p57Kip2 staining in individual CD34+ endothelial cells (Figure 2A, arrowheads) and a slightly stronger signal in subendothelial mesenchymal cells (Figure 2A,B, asterisk). By far the most intense staining was observed in patches of cells that were confirmed to be SA cells through co-staining with Ngfr (Figure 2A,B, arrows). To obtain more quantitative data, these different p57Kip2+ cell populations were isolated for real-time PCR analysis by fluorescence-activated cell sorting (Figure 2D, S1), using CD34 as a marker for endothelial cells, Ngfr for SA cells and Pdgfr $\beta$ for mesenchymal cells, excluding SA cells (arrowheads in Figure 2C). As p57Kip2 expression had been reported in adult HSCs ${ }^{30,32-36}$, we also sorted CD45+CD34+ haematopoietic stem and progenitor cells (HSPCS) from the AGM. The expression pattern did not change significantly between E11 and E12 and confirmed the immunohistochemistry data, with the strongest p57Kip2 expression detected in SA cells and reduced levels in endothelial and mesenchymal cells (Figure 2E,F). Considering the reported expression of p57Kip2 in adult HSCS and its essential role in their maintenance and quiescence, it was surprising to see that there was very little expression in AGM HSPCs. This not only confirms our previous findings that embryonic HSCs have very different properties from adult HSCs, including the way they regulate their cell cycle 27,28 , but it also suggests that p57Kip2 plays a non-cell autonomous role in HSC production in the AGM. 
p57Kip2 increases HSC numbers through an expansion of the catecholamine-secreting SA compartment.

Considering the strong expression of $\mathrm{p} 57 \mathrm{Kip} 2$ in the SNS and the role of SA cells in promoting HSC production in the AGM via catecholamine secretion, we analysed the effect of p57Kip2 deletion on SNS development. Immunohistochemical staining for the SA marker tyrosine hydroxylase (Th), the enzyme required for catecholamine synthesis, revealed an expansion of the SA compartment (Figure 3A), which we had previously observed in $T h$ in situ hybridisation experiments ${ }^{29}$ and have also confirmed by real-time PCR (Figure S2A). Interestingly, of all the embryonic tissues harbouring HSCS at that developmental stage, only the AGM expresses robust levels of Th (Figure S2B,C), suggesting that the functional interaction between the developing haematopoietic and sympathetic nervous system is specific to this tissue. As p57Kip2 is a cell cycle inhibitor, we hypothesised that the expansion of the SA compartment occurs via enhanced proliferation of these cells. Analysis of the cell cycle phases in Ngfr+ cells confirmed a higher percentage of SA cells in the S phase of the cell cycle in the absence of p57Kip2 (Figure 3B).

To establish whether the expansion of the SNS would translate into a higher production of catecholamines, which might then explain the increase in HSC numbers in the AGM, we measured catecholamine levels by High Performance Liquid Chromatography (HPLC). A pilot experiment revealed that noradrenaline is by far the most abundant catecholamine in the AGM and that its concentration is much higher there than in other haematopoietic tissues (Figure S2D). Noradrenaline levels at E11 were significantly higher in the p57Kip2-null AGMs; however, this had normalised at E12 (Figure 3C). Even though levels of dopamine, a precursor of noradrenaline, were much lower compared with noradrenaline (Figure S2D), we also saw significantly higher levels in E11 p57Kip2 KO AGMs, with a similar trend still visible at E12 (Figure 3D).

Catecholamines exert their effects by binding to adrenergic receptors, of which there are two families, the $\alpha$ and the $\beta$ family. To establish which family is involved in relaying the HSC promoting effect in the AGM, we treated embryos in utero with antagonists specific to these receptor subclasses. Blocking $\alpha$ adrenergic receptor activity had no effect on HSC numbers in the wild-type AGM and also did not abrogate the HSC expansion observed in p57Kip2 KO AGMs (Figure $3 E)$. In contrast, blocking $\beta$ adrenergic receptors had a profound negative impact on HSC activity in both the wild-type and p57Kip2 KO AGMs (Figure 3F). As there are three members of the $\beta$ adrenergic receptor family, we employed more specific antagonists, which revealed that the $\beta 2$ 
160

161

162

163

164

165

166

167

168

169

170

catecholamine - $\beta 2$ adrenergic receptor signalling axis (Figure $\mathbf{3 H}$ ). To further prove that the role of p57Kip2 in AGM HSC production is indeed upstream of catecholamine secretion from the SNS, we attempted to cross the p57Kip2 knockout line with a tyrosine hydroxylase (Th) knockout line, in which the enzyme required for catecholamine synthesis is deleted ${ }^{28}$. Surprisingly, the combination of a p57Kip2-null background with a Th-null background resulted in synthetic embryonic lethality, which excluded further analyses of double knockout embryos (Figure 3I).

\section{p57Kip2 is expressed in sympathoadrenal progenitor cells.}

To better define the cell type in which p57Kip2 is expressed, we performed antibody costainings with established markers of the stages of sympathoadrenal differentiation (Figure $4 \mathrm{~A}$ and reviewed in ${ }^{37}$ ). The sympathoadrenal lineage derives from Sox $10+$ neural crest cells, which migrate from the neural tube to the dorsal aorta at around E10. Upon arrival at the aorta, their commitment to the sympathoadrenal fate is initiated by the upregulation of the master regulatory transcription factor Phox $2 b$. Further maturation involves upregulation of Gata3, which is required for the expression of Th, which allows these cells to become fully mature, catecholamine-producing cells of either the adrenal anlage (ventrally) or the sympathetic ganglia (dorsally).

We detected little overlap between p57Kip2 and Sox10, with p57Kip2 being expressed in cells with a low or no Sox10 signal (Figure 4B). Overlap with the master regulator Phox2b, however, is complete. Further down the maturation pathway, p57Kip2 expression becomes more restricted, only partially overlapping with Gata3 and displaying an almost mutually exclusive pattern with Th. These results suggest that p57Kip2 expression initiates with the commitment of neural crest cells to the sympathoadrenal lineage, but that it is gradually downregulated as these cells fully mature to catecholamine-producing cells.

\section{Single-cell RNA-Seq reveals neural crest differentiation pathways}

To better define the differentiation pathway towards a SA fate, we performed single-cell RNA-Seq. As cell surface expression of Ngfr captures all SA cells (Figure 5A), we employed this marker to sort single cells from dissociated E11 AGMs by fluorescence-activated cell sorting, excluding mesenchymal cells (Ngfr+ Pdgfr $\beta$-). HSCs are preferentially located on the ventral side of the aorta ${ }^{38}$. Therefore, to detect factors that are upregulated in the ventral SA domain and that may contribute to the polarised localisation of HSCS, dissected aortae with the surrounding mesenchyme were first cut along the longitudinal axis to separate ventral from dorsal side before single cell preparation and cell sorting. Cell clustering and dimensionality reduction using t-SNE identified six clusters (Figure 5B). All clusters contained a mixture of ventrally and dorsally derived cells, apart 
194

195

196

197

198

199

200

201

202

203

204

205

206

207

208

209

210

211

212

213

214

215

216

217

218

219

220

221

222

223

224

225

226

227

from cluster 3, which was almost entirely composed of cells with a ventral origin. Cluster 4 appeared to be quite distinct from the remaining clusters and contained cells that displayed virtually no $\mathrm{Ngfr}$ expression (Figure $\mathbf{5 C}$ ). Instead, these cells expressed high levels of the pan-haematopoietic marker CD45, encoded by the Ptprc gene (Figure 5D) and other haematopoiesis-associated genes, such as members of the complement system, II10ra, Cd52, Cd53 and Pf4 (Figure S3A), hinting at a contamination by haematopoietic cells during the cell sorting. These cells further express high levels of Csf1r, Cx3cr1 and Runx1 (Figure 5E-G, S3A), but not Procr (coding for EPCR), Kit or Cd34 (Figure $5 \mathrm{H}-\mathrm{J})$, suggesting that they are macrophages resident in the mesenchyme, rather than haematopoietic stem or progenitor cells. Interestingly, Kit, normally considered to be a marker of HSPCS, is also expressed in a large portion of SA cells (Figure 5I).

Cell cycle prediction revealed that cluster 2 contained cells entirely in the G1 phase (Figure 5K). We therefore applied cell cycle correction, which resulted in the fusion of clusters 1 and 2. After this correction and removal of cluster 4, which contained contaminating macrophages, the remaining cells were now grouped into 4 clusters on which all further analyses were performed (Figure 5L). We performed differential expression analysis to determine the 40 most differentially expressed genes for each cluster (Figure S3B-G).

To assign the clusters to potential stages of SA differentiation, we investigated the expression of stage-specific markers amongst the clusters (Figure 4A). Sox10 expression was highest in cluster 1 (Figure 5M), suggesting that this cluster is en riched for neural crest cells, newly arrived at the dorsal aorta, while Th expression, the endpoint of SA differentiation, is mostly confined to cluster 4 (Figure $\mathbf{5 N}$ ). The late SA marker Phox $2 a$ is also upregulated in cluster 4 (Figure 50), while Gata3 expression initiates already in cluster 2 (Figure 5P). As suggested from the immunohistochemistry staining (Figure 4), Phox $2 b$ and p57Kip2 show a similar expression pattern. They are both upregulated in some cluster 1 cells, followed by the highest expression in cluster 2 and, at least in the case of p57Kip2, downregulation in Th-expressing cells of cluster 4 . It thus appears that cluster 1 and cluster 4 mark the two endpoints of SA differentiation, with cluster 2 being an intermediate stage.

\section{Notch signalling is downregulated upon SA maturation.}

To further confirm this potential differentiation pathway within the developing SA system, we performed cell lineage inference with Slingshot, a method that is specifically designed for modelling developmental trajectories in single-cell transcriptomic data and allows for integration of known developmental stages. Given that the sympathoadrenal lineage derives from Sox $10+$ neural crest cells, we defined the cluster containing the cells with the highest expression of Sox10 (Figure 
228

229

230

231

232

233

234

235

236

237

238

239

240

241

242

243

244

245

246

247

248

249

250

251

252

253

254

255

256

257

258

259

260

261

5M) as a starting point. Lineage inference analysis revealed that neural crest cells from this cluster (cluster 1) can take two alternative differentiation pathways, ending in clusters 3 (Lineage 2) or 4 (Lineage 1), via an intermediate population (cluster 2), in which divergence of the two fates is initiated (Figure 6A). Ngfr-expressing cells are found in all clusters, although expression was highest in the neural crest cluster (Figure 6B). Sox10 expression is downregulated along the trajectories, which occurs more gradually towards cluster 4 and more rapidly towards cluster 3 (Figure 6C). The trajectory towards cluster 4 appears to be the classic SA differentiation pathway since the end-point was marked by a sharp upregulation of Th expression (Figure 6D). Phox2a is similarly upregulated in cluster 4 (Figure 6E), whereas Gata3 expression, albeit highest in cluster 4, initiates noticeably earlier (Figure 6F), which correlates with our immunohistochemistry results (Figure 4B). Gata3 expression is known to be dependent on Phoxb ${ }^{39}$, the expression of which is clearly initiated prior to Gata3 (Figure 6G), again confirming our immunohistochemistry results (Figure 4B). Expression of p57Kip2/Cdkn1c is highest in the intermediate cluster 2, going into cluster 4 (Figure 6H, 5R), likely making this the stage where SA progenitors are expanded in the p57Kip2-null embryos.

We noticed that a number of members of the Notch signalling pathway were differentially expressed amongst the clusters (Figure 61-0). The expression of the three receptors, Notch1-3, was highest at the neural crest stage, and all three were downregulated by the final stage of SA differentiation in cluster 4 (Figure 6I-K). One of the main downstream targets and mediators of Notch activation is Hes1, which showed a similar expression pattern to Notch1-3 (Figure 6L). Another member of this family, Hes6, however, displayed the opposite expression pattern, with upregulation coincident with SA differentiation (Figure 6M). Interestingly, Hes6 was reported not to be activated by Notch signalling, but instead to serve as an inhibitor of Hes1, thereby promoting neural differentiation ${ }^{40}$. Two Notch ligands, DII3 and Dlk1, also showed upregulation along the classic SA differentiation pathway (Figure $6 \mathrm{~N}, 0$ ), and we have previously shown that Dlk1 expression in the SNS is Gata3-dependent ${ }^{24}$. Like Hes6, DII3 and Dlk1 are known antagonists of Notch signalling 41-44. Taken together, this suggests that Notch activity maintains neural crest identity and needs to be attenuated for these cells to able to commit to a SA fate, which may be achieved through the upregulation of Notch signalling inhibitors such as Hes6, DII3 and Dlk1. In support of this, it was demonstrated in chick embryos that expression of the constitutively active intracellular Notch domain inhibited sympathetic neuron differentiation from neural crest progenitors, while inhibition of Notch signalling increased neuron numbers ${ }^{45}$.

Neural crest cells can take an alternative differentiation path towards a mesenchymal fate upon arrival at the aorta. 
262 Our lineage inference analysis (Figure 6A) suggests that, upon arrival at the dorsal aorta, neural crest cells can differentiate down two alternative pathways. As described above, differentiation into cluster 4 cells represents the well-described SA differentiation path as marked by upregulation of key markers such as Tubb3 and Dbh (Figure S4). Interestingly, differentiation along the alternative pathway towards cluster 3 cells appears to be spatially restricted to the ventral side of the aorta (Figure $\mathbf{5 L}$ ). The region underneath the ventral endothelium contains a heterogeneous population of mesenchymal cells, many of which secrete factors known to support AGM haematopoiesis (reviewed in ${ }^{12}$ ). Furthermore, the existence of cells with properties of mesenchymal stem/stromal cells (MSCS) in the AGM at that time has been reported ${ }^{20}$. In that context, it is interesting that neuroepithelial cells have been shown to give rise to a transient wave of MSCs via a neural crest intermediate during development ${ }^{46}$. We therefore hypothesised that a subset of neural crest cells upon arrival at the aorta receives local signals that induce them to differentiate down the mesenchymal lineage instead of the SA lineage. Indeed, a subset of cells in cluster 3 express mesenchymal markers such as Bmper and Pdgfra (Figure 7A,B) ${ }^{23}$. To determine how similar the cluster 3 cells are to sub-aortic mesenchymal cells of the AGM, we integrated a single-cell RNA-Seq dataset from Pdgfrb+ Ngfr-mesenchymal cells isolated from the ventral halves of E11 AGMs. This showed that the putative Ngfr+ mesenchymal cells cluster more closely with the Pdgfrb+ Ngfr- subaortic mesenchymal cells, with some individual cells even becoming part of the bigger Pdgfrb+ Ngfrmesenchymal cluster when projected into a shared t-SNE space (Figure 7C). Differential expression analysis of cluster 3 cells compared to all other cells was subjected to Gene Set Enrichment Analysis (GSEA). This further supported the putative mesenchymal character of cluster 3, as significantly enriched Gene Ontology (GO) terms included 'Heart development' and 'Signaling pathways downstream of Tgfb'. To locate cluster 3 cells within the ventral AGM region, we carried out immunohistochemistry analysis of Dlk1, which was upregulated in cells of both cluster 3 and 4 (Figure $6 \mathrm{~N}$ ). Co-expression with Th identified cluster 4 cells in ventro- and dorsolateral patches, while Dlk1+ Th- cells were concentrated in the ventral mesenchyme (Figure 7D). Bmper has recently been identified as an important regulator for AGM HSC maturation ${ }^{23}$. We therefore checked for the presence of other important HSC niche factors and detected $\mathrm{CxCl} 12$ expression in the majority of cluster 3 cells (Figure 7E). In situ hybridisation confirmed strong expression of $C x c / 12$ in the ventral mesenchyme, while being excluded from the SA domain (outlined in red in Figure 7F). In addition, GO terms such as 'Cytokine-cytokine receptor interaction' and 'Chemokines bind chemokine receptors' were enriched.

The detection of HSC regulators prompted us to mine our dataset for other polarised 
296 derived Ngfr+ cells. Amongst the genes upregulated in the ventral cells were known HSC regulators,

297 such as $\mathrm{Mgp}^{47}, \mathrm{Ntf3}{ }^{48}$ and Tgfbi ${ }^{49}$, some of which have previously been shown to be expressed in

298 the ventral mesenchyme, such as $B m p e r{ }^{23}$ and $B m p 4{ }^{17,25}$ (Figure 7G). The expression of the majority

299 of the ventrally upregulated genes was restricted to cluster 3 cells (Figure $\mathbf{7 H}$ ), demonstrating that

300 they are the strongest contributor to the polarised expression of genes within the Ngfr+ populations

301 and may represent an important subset of HSC niche cells. The haematopoietic support function of

302 the ventrally derived cells is further supported by GO terms identified by GSEA, including 'Peptide

303 ligand-binding receptors', 'Factors involved in megakaryocyte development and platelet production',

304 'Systemic lupus erythematosus' and 'Retinol metabolism'.

305 Overall, our results suggest that neural crest cells not only regulate HSC development in the

306 aorta via the secretion of catecholamines from SA cells, which are expanded in the absence of

307 p57Kip2, but that they may also contribute a population of mesenchymal cells to the HSC niche that

308 secrete known HSC supportive factors.

309 
310

311

312

313

314

315

\section{DISCUSSION}

The cell cycle regulator p57Kip2 is strongly upregulated both at the time and in the region of HSC emergence; however, its absence was shown to expand HSC numbers in the AGM ${ }^{29}$. This study has now further analysed the underlying mechanisms, and we report here that $\mathrm{p} 57 \mathrm{Kip} 2$ acts non-cell autonomously through regulation of the size of the SA pool and therefore catecholamine levels. This is in stark contrast to the essential cell-intrinsic role of p57Kip2 in maintaining adult HSC functionality ${ }^{30,31}$. In fact, we show here that p57Kip2 expression in AGM HSCS is almost absent. This is another example of how embryonic HSCS differ from their adult counterparts in the way they regulate their cell cycle ${ }^{28}$, respond to DNA damage-inducing agents ${ }^{27}$ and are affected by mutations linked to haematological malignancies ${ }^{27,50}$. These differences are clearly important to regenerative medicine and human disease.

This study also delivers further insights into the way in which the definitive haematopoietic system and the sympathetic nervous system interact during their formation in development. Their interaction in the adult bone marrow niche has been well studied, with data supporting a direct effect of catecholamines via the $\beta 2$ adrenergic receptor on the surface of HSPCS ${ }^{51}$ or via an indirect mechanism mediated by the expression of the $\beta 3$ adrenergic receptor on stromal cells ${ }^{52}$. Our results with adrenergic receptor-specific inhibitors, together with our previous report that the $\beta 2$ adrenergic receptor is expressed on cells budding from the ventral aortic endothelium ${ }^{28}$, suggest that the effect of catecholamines (predominantly noradrenaline) is likely to be direct in the AGM. Interestingly, this interplay seems to be restricted to the AGM region, as the p57Kip2 knockout did not affect haematopoiesis in the yolk sac or the placenta and there was comparatively little $T h$ expression in these other tissues. This suggests that substantial catecholamine production at this point in development is exclusive to the AGM, as confirmed in our HPLC experiments. The fact that the HSC expansion in the p57Kip2-null AGMs translates into higher numbers of HSCs in the FL at the early stages of colonisation further suggests that the AGM is the main contributor to FL seeding at this stage.

By performing immunohistochemistry and single-cell RNA-Seq, we were able to identify the stage of SA differentiation that is expanded when the p57Kip2-mediated cell cycle break is removed, which corresponds to the Phox $2 b+$ stage following neural crest differentiation, but prior to final maturation as marked by Th expression. Interestingly, expression of p57Kip2 is often associated with terminal differentiation; however, this does not seem to be the case in the SNS, and the absence of p57Kip2 does not appear to impair SNS differentiation. It is therefore puzzling how the combined knockout of p57Kip2 and Th results in such a strong lethal phenotype, especially as either knockout on its own does not result in a decrease in Mendelian ratios before E12.5 (for Th) ${ }^{53,54}$ and E13.5 (for 
344 p57Kip2) ${ }^{55}$. p57Kip2 knockout embryos are hyperproliferative and may therefore by more acutely 345 dependent on an early supply of catecholamines; however, the exact cause for this synthetic lethality remains to be determined.

The single-cell transcriptome analysis of Ngfr+ cells in the AGM region has provided novel insights into the differentiation pathways that neural crest cells undertake once they have reached the dorsal aorta. In agreement with previous results from chick embryos ${ }^{45}$, it appears that downregulation of Notch signalling in SA progenitors is required for terminal differentiation. Interestingly, this also seems to be the case for the completion of haematopoietic specification from haemogenic endothelial cells in the AGM ${ }^{56-58}$, although the mechanisms may differ. Upregulation of Jag was shown to restrict Notch activity in haematopoietic specification, while we observed an upregulation of the Notch signalling inhibitors Dlk1, DII3 and Hes6.

Intriguingly, our cell lineage inference analysis highlighted a branching point in neural crest cell differentiation with one path leading to SA differentiation (cluster 4), while an alternative pathway results in the generation of cells with a mesenchymal character (cluster 3 ). There have been several reports of trunk neural crest cells differentiating into mesenchymal cells. An early study suggested that trunk neural crest cells produce the first, yet transient, wave of MSCs ${ }^{46}$, while subsequent studies provide evidence that at least a subset of bone marrow MSCs, with HSC niche activities, e.g. through the secretion of $\mathrm{Cxcl} 12$, are derived from trunk neural crest cells ${ }^{59,60}$, which may migrate to the bone marrow via the AGM ${ }^{61}$. Furthermore, a more recent study in zebrafish embryos reported Pdgf signalling-mediated migration of neural crest cells to the dorsal aorta where they promote HSC specification through direct interaction with haemogenic endothelial cells and provision of signals that are catecholamine-independent ${ }^{62}$. Interestingly, we have also detected upregulation of Pdgf signalling in cluster 3 cells, and they were shown to express HSC regulators such as $\mathrm{CxCl} 12$ and Bmp4. Whether these cells are indeed involved in AGM haematopoiesis and might even interact directly with haemogenic endothelial cells remains to be shown. Cxcl12 and Bmp4 also regulate the migration of neural crest cells and SA progenitors towards the dorsal aorta (reviewed in ${ }^{63}$ ), while $\mathrm{Cxcl} 12$ and Scf guide primordial germ cell (PGC) migration through the AGM region ${ }^{64}$. It may thus be an exciting possibility that cluster 3 cells are part of a signalling centre that coordinates the migration/regulation of several important cell types (HSCs, neural crest, PGCs) simultaneously; however, this awaits further studies. Future studies will also aim at identifying the local signals that promote neural crest cell differentiation towards a mesenchymal fate. 


\section{MATERIALS AND METHODS}

\section{Mice and tissue preparations}

Animal studies were performed following United Kingdom Home Office regulations. All animals were housed according to institutional guidelines and experiments complied with the animal welfare laws. To obtain embryos, p57Kip2 heterozygous females ${ }^{55}$ were crossed with C57BL/6J or CD45.1 males.

As $p 57$ Kip2 is imprinted, offspring receiving the deleted allele from the mother will have a complete knockout phenotype. For the $\mathrm{p} 57 /$ Th matings, $\mathrm{Th}+/$ - males ${ }^{28}$ were mated with $\mathrm{p} 57+/-\mathrm{Th}+/$ - females.

The day of vaginal plug detection was considered EO. Embryos smaller than their littermates or lacking a heartbeat were excluded. Single cell suspensions were obtained by treating AGMs, placentas and yolk sacs with collagenase (Alfa Aesar; $0.125 \%$ in phosphate-buffered saline) at $37^{\circ} \mathrm{C}$ for 45-90 minutes. Foetal livers were dissociated by pipetting.

\section{Transplantation Experiments}

Dissociated cell suspensions of embryonic tissues were intravenously injected into recipients with different CD45 isoforms that had received a split dose of 9.2-9.5 Gy of $\gamma$-irradiation. After 1 and 4 months, donor contribution to the recipients' peripheral blood was determined by flow cytometry, using anti-CD45.1-PE and anti-CD45.2-FITC antibodies (eBioscience). Mice were considered to be repopulated if the donor contribution was at or above 5\%. Statistics were performed on GraphPad Prism and the Mann-Whitney $U$-test was used to determine significance levels.

\section{Adrenergic blockers administration in vivo}

400 Each adrenergic receptor was blocked from E8 of gestation. $\alpha$ adrenergic receptors (Adra1 and Adra2) were blocked by intra-peritoneal (i.p.) administration of phentolamine $(5 \mathrm{mg} / \mathrm{kg})$. $\beta$ adrenergic receptors (Adrb1, Adrb2 and Adrb3) were blocked by oral administration of propranolol (0.5 g/l of drinking water) or, for specific $\beta$ adrenergic receptor inhibition, i.p. administration of betaxolol (1mg/kg) for Adrb1, ICl 118,551 (1mg/kg) for Adrb2 and SR 59230A (5 mg/kg) for Adrb3, all from Sigma. All inhibitors were diluted in PBS, apart from propranolol which was diluted in drinking water and SR 59230A which was diluted in PBS containing 1\% DMSO. All blockers were administered 
410

411

412

413

414

415

416

417

418

419

420

421

422

423

424

425

426

427

428

429

430

431

432

433

434

435

436

437

438

439

440

441

442

443

High Performance Liquid Chromatography (HPLC) was performed in the Psychology Analytical Laboratory (Psychology Department, University of Cambridge). Haematopoietic tissues were dissected and snap-frozen in liquid nitrogen. Perchloric acid (PCA; Fisher Chemicals) was added to the tissues and the samples were homogenised. The samples were spun and the diluted supernatant (1:10 in 0.2 M PCA buffer) was auto-injected into the HPLC machine (234 Autoinjector, Gilson; Hyperclone, 5u, BDS, C18, 100A, $100 \times 4.60 \mathrm{~mm}$ column, Phenomenex). The HPLC system mobile phase consisted of $31.90 \mathrm{~g}$ citric acid, $2 \mathrm{~g}$ sodium acetate, $460 \mathrm{mg}$ Octanesulfonic acid, $30 \mathrm{mg}$ Ethylenediamine tetra acetic acid (EDTA), $150 \mathrm{ml}$ Ethanol and distilled water up to $1 \mathrm{~L}$; pH was adjusted to 3.6 with $\mathrm{NaOH}$ (all from Fisher Chemicals, HPLC grade). The following standards were used to calibrate the HPLC equipment prior to measurement acquisition: NA (noradrenaline), EP (epinephrine/adrenaline) and DA (dopamine), all from Sigma. The signal was detected by an electrochemical detector (ESA, Coulochem II; Parameters: E1 -200 mw, R1 10uA, E2 250 mw, R2 200 $\mathrm{nA}$, flow rate: $0.750 \mathrm{ml}$ per minutes, pressure: $129 \mathrm{bar}$ ) and data were collected by the Dionex Data System (Chromeleon). Statistics were performed on GraphPad Prism and unpaired $t$-test was used to determine significance levels, $n=14$ per genotype/stage; $n=56$ in total.

\section{Flow Cytometry and Cell Sorting}

The staining in all the experiments was performed on ice in the dark for 30 minutes. After washing, cells were resuspended in buffer (PBS/2\% FCS/ $1 \%$ penicillin/streptomycin) containing a viability dye from the Sytox series (Life Technologies) or DAPI (Sigma). All antibodies were purchased from eBioscience, $B D$ and BioLegend, unless otherwise stated. The following antibodies were used: CD45.1 (A20), CD45.2 (104), CD34 (RAM34), Pdgfrß (APB5), CD45 (104), Ngfr (polyclonal; ANT-007AO; Alomone Labs Ltd). Cell cycle analysis was performed with DAPI staining. Data were acquired on a Fortessa instrument or cells sorted on Influx or ARIA instruments (all from BD Biosciences). Data were analysed using FlowJo software (vX.0.6, Tree Star, Inc.).

\section{Immunohistochemistry}

Embryos were fixed in 4\% PFA (Sigma) in PBS for 1.5 hours at $4^{\circ} \mathrm{C}$ and equilibrated in $30 \%$ sucrose (Fisher Scientific) at $4^{\circ} \mathrm{C}$ overnight. The following day, the embryos were frozen in OCT (SakuraFinetek) on dry ice and kept at $-80^{\circ} \mathrm{C}$ until they were sectioned on a cryostat (OTF-5000, Bright Instruments and CM1900, Leica). Blocking solution (2\% serum from the animal that the secondary antibody was raised in and $0.4 \%$ Triton-X 100 in PBS or $0.1 \%$ Tween (all from Sigma)) was added for 1 hour at room temperature (RT). Primary antibodies were then added in blocking solution and left at $4^{\circ} \mathrm{C}$ overnight. Primary antibodies were: p57Kip2 (rabbit H-91; 1:500, Santa Cruz Biotechnology), Th 
444 (mouse LNC1, 1:300, Millipore), Gata3 (goat polyclonal, 1:200, R\&D Systems), CD34 (FITC RAM34,

445 1:200, BD), Phox2b (guinea pig, 1:200, kind gift from J.F. Brunet), Ngfr (goat C-20, 1:300, Santa Cruz

446 Biotechnology) and Sox10 (goat N-20, 1:250, Santa Cruz Biotechnology). The next day, the secondary

447 antibodies were added for $1-1.5$ hours at RT. Secondary antibodies were: Alexa555 goat anti-rabbit

448 (1:500), Alexa647 chicken anti-mouse (1:2000), Alexa488 donkey anti-goat (1:300) and guinea pig

449 (Life Technologies). Subsequently, DAPI solution was added to each slide (1:5000 dilution from 5

$450 \mathrm{mg} / \mu \mathrm{l}$ stocks), which were incubated for 5 minutes. Slides were mounted with $150 \mu \mathrm{l}$ of Mounting

451 Medium Fluoromount-G (Southern Biotech). The images were acquired on an Axioimager Z2 upright

452 Microscope (Zeiss) (Camera: ORCA Flash 4 v.2, Objectives: 40x Oil and 63x Oil). Extended Depth of

453 Focus images were created from Z-stacks of separate tiles that were then stitched together.

454 Acquisition and processing was performed using the imaging software ZEN 2011 (Zeiss).

455

456 In situ hybridisation

457 Cryosections from frozen embryos prepared as above were air-dried for 20 minutes and fixed in $4 \%$

458 PFA/PBS for ten minutes at room temperature, washed three times with PBS and then acetylated

$459(1.3 \% \mathrm{v} / \mathrm{v}$ triethanolamine, $0.175 \% \mathrm{v} / \mathrm{v}$ hydrochloric acid and $0.25 \% \mathrm{v} / \mathrm{v}$ acetic anhydride in nuclease-

460 free water) for 10 minutes at room temperature. After three washes with PBS, slides were incubated

461 in hybridisation buffer $(50 \%$ formamide, $5 x$ SSC, 1 Denhardts, $0.02 \%$ polyvinylpyrrolidone, $0.02 \%$

462 bovine serum albumin), $0.1 \%$ Tween-20, $250 \mu \mathrm{g} / \mathrm{ml}$ MRE 600 tRNA, 500 $\mu \mathrm{g} / \mathrm{ml}$ salmon sperm DNA) for

463 one hour at RT. Digoxigenin-labelled $\mathrm{CxCl} 12$ riboprobe was diluted $100 \mathrm{pg}$ in $100 \mu$ l hybridization

464 buffer, denatured at $80^{\circ} \mathrm{C}$ for five minutes and then added to the slides. Slides were covered in

465 parafilm and hybridised overnight at $65^{\circ} \mathrm{C}$ in a humidified box. The following day, slides were placed

466 in $5 \times S S C$ at $65^{\circ} \mathrm{C}$ to allow the coverslips to detach before four washes in $0.2 \times S S C$ at $65^{\circ} \mathrm{C}$ for 25

467 minutes each and a final wash for five minutes at room temperature. Slides were then washed in

468 buffer $1(0.1 \mathrm{M}$ Tris at $\mathrm{pH} 7.5,0.15 \mathrm{M} \mathrm{NaCl})$ for five minutes and pre-blocked in buffer 2 (10\% heat-

469 inactivated sheep serum in buffer 1) for at least one hour at room temperature. They were

470 incubated overnight at $4^{\circ} \mathrm{C}$ with 1:4000 alkaline phosphatase-conjugated anti-digoxigenin antibody

471 (Roche) in buffer 2. On the next day, slides were washed in buffer 1, equilibrated in buffer $3(0.1 \mathrm{M}$

472 Tris at $\mathrm{pH} 9.5,0.1 \mathrm{M} \mathrm{NaCl}, 50 \mathrm{mM} \mathrm{MgCl} 2,0.24 \mathrm{mg} / \mathrm{ml}$ levamisole) for five minutes at room

473 temperature before being incubated in the dark with $2 \%$ Nitro-Blue Tetrazolium Chloride/5-Bromo-

474 4-Chloro-3?-Indolyphosphate $p$ - Toluidine Salt (NBT/BCIP; Roche) in buffer 3 at room temperature

475 until staining developed. To stop the staining, slides were rinsed with TE solution (10mM Tris, pH7.5,

$4761 \mathrm{mM}$ EDTA), then water, fixed for 30 minutes in $4 \%$ PFA/PBS, then rinsed again with TE followed by 
477 water before being mounted in Hydromount mounting medium (National Diagnostics). Images were

478

479

480

481 taken with a Zeiss AxioSkop2 microscope.

Cxcl12 and p57Kip2 fragments for riboprobe synthesis were amplified from E11 AGM CDNA by RTPCR using the following primers: Cxcl12 fwd: TTTCACTCTCGGTCCACCTC, Cxcl12 rev: TAATTTCGGGTCAATGCACA; p57Kip2 fwd: CTGACCTCAGACCCAATTCC, p57Kip2 rev: GATGCCCAGCAAGTTCTCTC. The gel-purified fragment was cloned into the $\mathrm{p}$-GEM-T Easy vector (Promega) and digoxigenin-labelled probes generated by in vitro transcription using a DIG RNA labelling kit (Roche).

\section{Gene Expression Analysis by real-time PCR}

RNA was extracted using the miRNAeasy Micro kit (Qiagen) according to manufacturer instructions, and RNA quality was assessed by the High Sensitivity RNA Assay (Agilent Technologies) on an Agilent Tapestation instrument. The iScript Advanced cDNA Synthesis Kit for RT-qPCR (Bio-rad) was used according to manufacturer instructions for cDNA synthesis. 2x Sybr (Brilliant III Ultra-Fast SYBR QPCR; Agilent Technologies, UK) was used for qPCR on a LightCycler 480 system (Roche Diagnostics, UK). The program was set as follows: $95^{\circ} \mathrm{C}$ for 5 minutes, 55 cycles of $95^{\circ} \mathrm{C}$ for 10 seconds, $60^{\circ} \mathrm{C}$ for 10 seconds and $72^{\circ} \mathrm{C}$ for 5 seconds, followed by $95^{\circ} \mathrm{C}$ for 5 seconds and $65^{\circ} \mathrm{C}$ for 1 minute. At the end of the qPCR program, a melting curve was run at continuous acquisition mode $\left(97^{\circ} \mathrm{C}, 5\right.$ seconds $\left./{ }^{\circ} \mathrm{C}\right)$, followed by a cooling step $\left(40^{\circ} \mathrm{C}\right.$ for 10 seconds). The $\mathrm{Ct}$ values were retrieved the end the run and data were analysed in Microsoft Excel according to the $\Delta \mathrm{Ct}$ method. All samples were run in at least three biological replicates, each of which was run in technical triplicates. Graphs were made on GraphPad Prism and the student $t$-test was used to determine significance levels. Primer sequences were: p57Kip2: $\mathrm{F}:$ 5?-CAGCGGACGATGGAAGAACT-3?]， R: 5?-CTCCGGTTCCTGCTACATGAA-3?]; Gata3: F: 5'-CGAAACCGGAAGATGTCTAGC-3'， R: 5'-AGGAACTCTTCGCACACTTGG-3'; Th: F: 5'tATGGAGAGCTCCTGCACTC-3', R: 5'-TTCTCGAGCTTGTCCTTGGC-3'; b-Actin: F: 5'GGCTGTATTCCCCTCCATCG-3', R: 5'-CCAGTTGGTAACAATGCCATGT-3'.

\section{Library preparation for SCRNA-Seq}

scRNA-seq analysis was performed using the Smart-seq2 protocol as described previously ${ }^{65}$. Single Ngfr+Pdgfrb- or Ngfr-Pdgfrb+ cells were sorted by FACS directly into individual wells of a 96-well plate containing lysis buffer ( $0.2 \%$ RNase inhibitor (Ambion, Thermo Fisher Scientific) in Triton X-100 (Sigma)), and libraries were prepared using the Illumina Nextera XT DNA preparation kit. Pooled libraries were run on the Illumina Hi-Seq 2500 and reads aligned using STAR ${ }^{66}$. 


\section{Read alignment}

512 Reads were aligned using Kallisto (Linux v0.43.0, ${ }^{67}$ ) using parameters kallisto quant -513 plaintext --bias --single -fragment-length=200 --fragment-length=200 $514--s d=20$.

515 Samples were mapped to Mus_musculus.GRCm38.cdna.all.fa version of the transcriptome 516 downloaded from Ensembl (www.ensembl.org) Feb. 2017. This library was appended with the 517 ERCC92 spikes (ERCC92.fa) downloaded from www.thermofisher.com and appended to the transcript library. Read quality from individual libraries was assessed using FastQC (https://www.bioinformatics.babraham.ac.uk/projects/fastqc) and MultiQC, ${ }^{68}$ ).

520 Transcripts were trimmed using Cutadapt ${ }^{69}$ ) using the command cutadapt -a CTGTCTCTTATA -f fastq -e $0.1-0 \quad 3$-q 20 -m 20 ).

\section{Data pre-processing}

Data were pre-processed following the single-cell transcriptomics workflow of Lun et al. ${ }^{70}$ using $R$ version 4.0.0 under 64bit Windows $>=8$. Data were imported into $R$ using the scater Bioconductor package (scater_1.18.6, ${ }^{71}$ ) function readKallistoResults. Transcript level quantitation was also collapsed to gene at this stage using a transcript to gene mapping table generated from Ensembl Transcript Stable ID and Gene Stable ID. All downstream analysis was carried out at gene level. Ensembl IDs were mapped to MGI Gene Symbols using Bioconductor mouse gene annotation files (org.Mm.eg.db_3.6.0).

Following the Lun et al. ${ }^{70}$ workflow, cell quality was assessed based on library size, number of expressed features in each library, percentage of reads aligned to mitochondrial genes (obtained from Ensembl) and percentage of reads aligned to spike-in transcripts. We used the median absolute deviation (MAD) definition of outliers to remove putative low-quality cells from subsequent analysis: cells with any quality measurement more extreme than 3 MADs from the median were removed. Similarly, cells which had outlying proportions of mitochondrial genes or samples with low numbers of unique genes were also removed. Removing cells with a high proportion of reads mapping to spike-in RNAs left only one cell in the HSC1 sample group after filtering. This cell was removed from

540 the data and the HSC1 group eliminated from further analysis. The HSC2 group was referred to as 541 HSC in the rest of the analysis. Overall, 335 cells consisting of 65 HSC2, 93 Dorsal, 89 Ventral and 88 542 Mesenchymal cells passed initial filtering. We filtered genes with low abundance (those with mean 543 count across all cells less than 1), since these genes are likely to be dominated by drop-out events, limiting their usefulness in further analysis. 14,109 genes passed this filtering step. 
545 We used the computeSumFactors function in the scran $\mathrm{R}$ package ${ }^{70}$ to normalise within each plate

546 and then scale plate samples to each other. Read counts mapping to ERCC spikes were normalised

547 separately to the expression data and not used for normalisation of expression samples. In this

548 analysis we cannot completely exclude confounding plate-effects. However, internal control marker

549 and cell profiles were used to assess the normalisation and are consistent with the expected biology.

\section{Cell cycle correction}

552 Following the workflow of Lun et al. ${ }^{70}$, we used the Cyclone prediction method ${ }^{72}$ to assign cells into 553 cell cycle phases based on the gene expression data. Cells were assigned to a cell cycle phase if the 554 score for that phase was greater than 0.5. Cells were considered of ambiguous cell cycle phase 555 otherwise. Cells were initially visualised using their cell cycle phase before removal of this effect 556 using limma $\left(v 3.46 .0,{ }^{73}\right)$ by fitting a linear model ( G1+G2M $\left.+S\right)$ and decomposing the variance. The 557 trendVar function was used to fit a loess smoothed line to the gene specific variances and the 558 decomposeVar function was used to decompose the variances into biological and technical 559 variances. Genes were selected with the biological component of the variance $>=0.5$ and FDR $<0.2$ 560 against the null hypothesis that biological variance equals 0 . This generated a set of highly variable 561 genes that was used as a set of genes for dimensional reduction with t-SNE.

\section{Cell clustering and dimensional reduction}

564 t-distributed Stochastic Neighbour Embedding (t-SNE; ${ }^{74}$ ) was used for dimensionality reduction. $\mathrm{t}$ 565 SNE visualisations were generated with varying settings of the perplexity parameter $(5,10$ and 20) 566 and the clusters obtained found to be robust. A t-SNE perplexity value of 10 was chosen as 567 representative. t-SNE was performed across all the data and coloured by group: HSC2, Dorsal, 568 Mesenchymal and Ventral cells. A set of predetermined marker genes for Dorsal/Ventral (Phox2b, 569 Ngfr, Sox10, Cdkn1c, Th, Gata3), HSC (Ptprc, Kit, Procr, Runx1, Cd34) and Mesenchymal (Pdgfra, 570 Col1a2, Dlk1, Cspg4, Acta2, Pdgfrb and Cxcl12) were used to confirm the biological identify of each 571 cluster.

572 A group of cells that were from Dorsal/Ventral origin were selected from the data and used to 573 identify highly variable genes, dimensionally reduced using t-SNE and split into six clusters using k574 means clustering. Robustness of the computed clusters was confirmed using the Dynamic Tree Cut 575 method. Analysis of the computed clusters revealed that the cells in one cluster expressed a range of 576 known macrophage markers; cells in this cluster were removed from downstream analysis. Further 577 analysis of the remaining clusters identified one cluster that was purely defined by cell cycle identity; 
578 following batch correction for cell cycle using limma and reclustering, cells in this cluster were found

579 to be redistributed among the remaining four clusters.

580

\section{Differential expression analysis}

582 The edgeR Bioconductor package $\left(\mathrm{v} 3.32 .1 ;{ }^{75}\right)$ was used to identify significantly differentially 583 expressed genes between cell clusters. Differential expression results were filtered by fold change 584 and an FDR threshold of 0.2 . The top 40 differentially expressed genes for each cluster were computed using fold change ranking and a fixed FDR threshold of 0.2 .

\section{Cell lineage inference analysis}

588 The Slingshot Bioconductor package $\left(\right.$ v.1.8.0; ${ }^{76}$ ) was used to perform cell lineage inference analysis.

589 The expression data and cell cluster labels were used as input to infer the global lineage structure.

590 Based on this structure, two smooth cell lineages were constructed and pseudotime variables were 591 inferred for both smooth lineages.

\section{Gene set enrichment analysis}

594 The GSEAPreranked tool (GSEA 4.1.0, build 27; ${ }^{77}$ ) was used for gene set enrichment analysis. To 595 create the ranked gene list, genes were filtered to remove genes with $\log C P M<=0$; remaining genes 596 were ranked based on log fold change. Gene sets were obtained from the ConsensusPathDB-mouse 597 interaction database ${ }^{78}$; gene sets containing less than 15 genes or more than 500 genes were 598 excluded from further analysis. The default GSEA enrichment statistic (weighted) was used, 599 corresponding to a value of $p=1$ in the GSEA enrichment score calculation ${ }^{77}$. GSEA's meandiv 600 method (default) was used to normalise enrichment scores to account for differences in gene set 601 size and allow analysis over gene sets. Multiple hypothesis testing was corrected using sample 602 permutation $(n=1000)$.

603

\section{Data accessibility}

605 The single cell RNA-seq data from this study have been deposited in the Gene Expression Omnibus 606 database $\left(\right.$ GEO, ${ }^{79}$ ) under the accession number GSE139052.

607

608

\section{ACKNOWLEDGMENTS}

610 We are indebted to the staff of the animal facilities both at the Cambridge Institute for Medical 
612 to the flow cytometry teams at both of these institutes, Dr. Reiner Schulte, Dr. Chiara Cossetti, and

613 Michal Maj in Cambridge and Fiona Rossi and Dr Claire Cryer in Edinburgh, for excellent cell sorting

614 services and help with flow cytometry analyses. We are also very grateful to Dr Brunet for providing

615 us with the Phox $2 b$ antibody. Core facilities at the Edinburgh Centre for Regenerative Medicine were

616 supported by centre grant MR/K017047/1. This work was funded by a Bloodwise Bennett Senior

617 Fellowship (10015 to K.O.) and the Kay Kendall Leukaemia Fund (to K.O.). This research was also

618 funded in part by the Wellcome Trust and the UKRI Medical Research Council. For the purpose of

619 open access, the author has applied a CC BY public copyright licence to any Author Accepted

620 Manuscript version arising from this submission.

621

\section{AUTHOR CONTRIBUTIONS}

623 C.K. performed and designed the majority of experiments and wrote the manuscript; L.N., A.M.K.

624 and K.K. performed bioinformatics analyses; N.K.W. and B.G. provided advice and assistance with

625 scRNA-Seq experiment; K.X., B.M.-S. and C.M. performed experiments; S.T. designed, performed and

626 supervised the bioinformatics analysis of the scRNA-Seq data; K.O. conceived and supervised the

627 study and wrote the manuscript.

628

629

\section{DECLARATION OF INTERESTS}

630 The authors have no conflicts of interest to declare.

631

632 


\section{REFERENCES}

6341 Medvinsky, A. \& Dzierzak, E. Definitive hematopoiesis is autonomously initiated by the AGM 635 region. Cell 86, 897-906 (1996).

6362 Muller, A. M., Medvinsky, A., Strouboulis, J., Grosveld, F. \& Dzierzak, E. Development of 637 hematopoietic stem cell activity in the mouse embryo. Immunity 1, 291-301 (1994).

6383 Ciau-Uitz, A., Monteiro, R., Kirmizitas, A. \& Patient, R. Developmental hematopoiesis: 639 ontogeny, genetic programming and conservation. Experimental hematology 42, 669-683, 640 doi:10.1016/j.exphem.2014.06.001 (2014).

6414 Dzierzak, E. \& de Pater, E. Regulation of Blood Stem Cell Development. Current topics in

5 Lacaud, G. \& Kouskoff, V. Hemangioblast, hemogenic endothelium, and primitive versus definitive hematopoiesis. Experimental hematology 49, 19-24, doi:10.1016/j.exphem.2016.12.009 (2017).

6 Ottersbach, K. Endothelial-to-haematopoietic transition: an update on the process of making blood. Biochem Soc Trans 47, 591-601, doi:10.1042/BST20180320 (2019).

7 Boisset, J. C. et al. In vivo imaging of haematopoietic cells emerging from the mouse aortic endothelium. Nature 464, 116-120, doi:10.1038/nature08764 (2010).

8 Gordon-Keylock, S., Sobiesiak, M., Rybtsov, S., Moore, K. \& Medvinsky, A. Mouse extraembryonic arterial vessels harbor precursors capable of maturing into definitive HSCs. Blood 122, 2338-2345, doi:10.1182/blood-2012-12-470971 (2013).

$9 \mathrm{Li}, \mathrm{Z}$. et al. Mouse embryonic head as a site for hematopoietic stem cell development. Cell stem cell 11, 663-675, doi:10.1016/j.stem.2012.07.004 (2012).

10 Rhodes, K. E. et al. The emergence of hematopoietic stem cells is initiated in the placental vasculature in the absence of circulation. Cell stem cell 2, 252-263, doi:10.1016/j.stem.2008.01.001 (2008).

11 Taoudi, S. et al. Extensive hematopoietic stem cell generation in the AGM region via maturation of VE-cadherin+CD45+ pre-definitive HSCs. Cell stem cell 3, 99-108, doi:10.1016/j.stem.2008.06.004 (2008).

12 Mirshekar-Syahkal, B., Fitch, S. R. \& Ottersbach, K. Concise review: From greenhouse to garden: the changing soil of the hematopoietic stem cell microenvironment during development. Stem cells 32, 1691-1700, doi:10.1002/stem.1680 (2014).

13 Ohneda, O. et al. WECHE: a novel hematopoietic regulatory factor. Immunity 12, 141-150 (2000).

14 Oostendorp, R. A. et al. Stromal cell lines from mouse aorta-gonads-mesonephros subregions are potent supporters of hematopoietic stem cell activity. Blood 99, 1183-1189 (2002).

15 Oostendorp, R. A. et al. Embryonal subregion-derived stromal cell lines from novel temperature-sensitive SV40 T antigen transgenic mice support hematopoiesis. Journal of cell science 115, 2099-2108 (2002).

16 Charbord, P. et al. A systems biology approach for defining the molecular framework of the hematopoietic stem cell niche. Cell stem cell 15, 376-391, doi:10.1016/j.stem.2014.06.005 (2014).

17 Durand, C. et al. Embryonic stromal clones reveal developmental regulators of definitive hematopoietic stem cells. Proceedings of the National Academy of Sciences of the United States of America 104, 20838-20843, doi:10.1073/pnas.0706923105 (2007).

18 Istvanffy, R. et al. Stromal pleiotrophin regulates repopulation behavior of hematopoietic stem cells. Blood 118, 2712-2722, doi:10.1182/blood-2010-05-287235 (2011).

19 Renstrom, J. et al. Secreted frizzled-related protein 1 extrinsically regulates cycling activity and maintenance of hematopoietic stem cells. Cell stem cell 5, 157-167, doi:10.1016/j.stem.2009.05.020 (2009). 


\begin{tabular}{|c|c|c|}
\hline 683 & 20 & $\begin{array}{l}\text { Mendes, S. C., Robin, C. \& Dzierzak, E. Mesenchymal progenitor cells localize within } \\
\text { hematopoietic sites throughout ontogeny. Development 132, 1127-1136, }\end{array}$ \\
\hline 35 & & \\
\hline $\begin{array}{l}686 \\
687\end{array}$ & 21 & $\begin{array}{l}\text { risan, M. et al. BMP signalling differentially regulates distinct haematopoietic stem cell } \\
\text { ypes. Nature communications } 6,8040 \text {, doi: } 10.1038 / \text { ncomms } 9040 \text { (2015). }\end{array}$ \\
\hline $\begin{array}{l}688 \\
689\end{array}$ & 22 & $\begin{array}{l}\text { Crisan, M. et al. BMP and Hedgehog Regulate Distinct AGM Hematopoietic Stem Cells Ex } \\
\text { Vivo. Stem cell reports 6, 383-395, doi:10.1016/j.stemcr.2016.01.016 (2016). }\end{array}$ \\
\hline $\begin{array}{l}690 \\
691 \\
692\end{array}$ & 23 & $\begin{array}{l}\text { McGarvey, A. C. et al. A molecular roadmap of the AGM region reveals BMPER as a novel } \\
\text { regulator of HSC maturation. The Journal of experimental medicine 214, 3731-3751, } \\
\text { doi:10.1084/jem.20162012 (2017). }\end{array}$ \\
\hline $\begin{array}{l}693 \\
694\end{array}$ & 24 & $\begin{array}{l}\text { Mirshekar-Syahkal, B. et al. Dlk1 is a negative regulator of emerging hematopoietic stem and } \\
\text { progenitor cells. Haematologica 98, 163-171, doi:10.3324/haematol.2012.070789 (2013). }\end{array}$ \\
\hline $\begin{array}{l}695 \\
696 \\
697\end{array}$ & 25 & $\begin{array}{l}\text { ouilhol, C. et al. Inductive interactions mediated by interplay of asymmetric signalling } \\
\text { nderlie development of adult haematopoietic stem cells. Nature communications } 7,10784 \text {, } \\
\text { oi:10.1038/ncomms10784 (2016). }\end{array}$ \\
\hline $\begin{array}{l}698 \\
699 \\
700\end{array}$ & 26 & $\begin{array}{l}\text { vernogeau, L. et al. Multispecies RNA tomography reveals regulators of hematopoietic stem } \\
\text { ell birth in the embryonic aorta. Blood 136, 831-844, doi:10.1182/blood.2019004446 } \\
\text { 020). }\end{array}$ \\
\hline $\begin{array}{l}701 \\
702 \\
703\end{array}$ & 27 & $\begin{array}{l}\text { Mascarenhas, M. I. et al. Analysis of Jak2 signaling reveals resistance of mouse embryonic } \\
\text { hematopoietic stem cells to myeloproliferative disease mutation. Blood 127, 2298-2309, } \\
\text { doi:10.1182/blood-2015-08-664631 (2016). }\end{array}$ \\
\hline $\begin{array}{l}704 \\
705 \\
706\end{array}$ & 28 & $\begin{array}{l}\text { Fitch, S. R. et al. Signaling from the sympathetic nervous system regulates hematopoietic } \\
\text { stem cell emergence during embryogenesis. Cell stem cell 11, 554-566, } \\
\text { doi:10.1016/j.stem.2012.07.002 (2012). }\end{array}$ \\
\hline $\begin{array}{l}707 \\
708 \\
709\end{array}$ & 29 & $\begin{array}{l}\text { Mascarenhas, M. I., Parker, A., Dzierzak, E. \& Ottersbach, K. Identification of novel regulators } \\
\text { of hematopoietic stem cell development through refinement of stem cell localization and } \\
\text { expression profiling. Blood 114, 4645-4653, doi:10.1182/blood-2009-06-230037 (2009). }\end{array}$ \\
\hline $\begin{array}{l}710 \\
711\end{array}$ & 30 & $\begin{array}{l}\text { latsumoto, A. et al. p57 is required for quiescence and maintenance of adult hematopoietic } \\
\text { em cells. Cell stem cell 9, 262-271, doi:10.1016/j.stem.2011.06.014 (2011). }\end{array}$ \\
\hline $\begin{array}{l}712 \\
713 \\
714\end{array}$ & 31 & $\begin{array}{l}\text { Zou, P. et al. } \mathrm{p} 57(\mathrm{Kip} 2) \text { and } \mathrm{p} 27(\mathrm{Kip} 1) \text { cooperate to maintain hematopoietic stem cell } \\
\text { quiescence through interactions with Hsc70. Cell stem cell 9, 247-261, } \\
\text { doi:10.1016/j.stem.2011.07.003(2011). }\end{array}$ \\
\hline $\begin{array}{l}715 \\
716\end{array}$ & 32 & $\begin{array}{l}\text { Miyamoto, K. et al. Foxo3a is essential for maintenance of the hematopoietic stem cell pool. } \\
\text { Cell stem cell 1, 101-112, doi:10.1016/j.stem.2007.02.001 (2007). }\end{array}$ \\
\hline $\begin{array}{l}717 \\
718\end{array}$ & 33 & $\begin{array}{l}\text { Passegue, E., Wagers, A. J., Giuriato, S., Anderson, W. C. \& Weissman, I. L. Global analysis of } \\
\text { proliferation and cell cycle gene expression in the regulation of hematopoietic stem and }\end{array}$ \\
\hline $\begin{array}{l}719 \\
720\end{array}$ & & $\begin{array}{l}\text { progenitor cell fates. The Journal of experimental medicine 202, 1599-1611, } \\
\text { doi:10.1084/jem.20050967(2005). }\end{array}$ \\
\hline $\begin{array}{l}721 \\
722 \\
723\end{array}$ & 34 & $\begin{array}{l}\text { Qian, H. et al. Distinct roles of integrins alpha6 and alpha4 in homing of fetal liver } \\
\text { hematopoietic stem and progenitor cells. Blood 110, 2399-2407, doi:10.1182/blood-2006- } \\
\text { 10-051276 (2007). }\end{array}$ \\
\hline $\begin{array}{l}723 \\
724\end{array}$ & 35 & Wilson, N. K. et al. Combined Single-Cell Functional and Gene Expression Analysis Resolves \\
\hline $\begin{array}{l}725 \\
726\end{array}$ & & $\begin{array}{l}\text { Heterogeneity within Stem Cell Populations. Cell stem cell 16, 712-724, } \\
\text { doi:10.1016/j.stem.2015.04.004(2015). }\end{array}$ \\
\hline $\begin{array}{l}727 \\
728 \\
729\end{array}$ & 36 & $\begin{array}{l}\text { Yamazaki, S. et al. Cytokine signals modulated via lipid rafts mimic niche signals and induce } \\
\text { hibernation in hematopoietic stem cells. The EMBO journal 25, 3515-3523, } \\
\text { doi:10.1038/sj.emboj.7601236(2006). }\end{array}$ \\
\hline $\begin{array}{l}730 \\
731\end{array}$ & 37 & $\begin{array}{l}\text { Huber, K. The sympathoadrenal cell lineage: specification, diversification, and ne } \\
\text { perspectives. Developmental biology } 298,335-343 \text {, doi:10.1016/j.ydbio.2006.07.010 (2006) }\end{array}$ \\
\hline $\begin{array}{l}732 \\
733\end{array}$ & 38 & $\begin{array}{l}\text { Taoudi, S. \& Medvinsky, A. Functional identification of the hematopoietic stem cell niche in } \\
\text { the ventral domain of the embryonic dorsal aorta. Proceedings of the National Academy of }\end{array}$ \\
\hline
\end{tabular}


Sciences of the United States of America 104, 9399-9403, doi:10.1073/pnas.0700984104 (2007).

39 Tsarovina, K. et al. Essential role of Gata transcription factors in sympathetic neuron development. Development 131, 4775-4786, doi:10.1242/dev.01370 (2004).

40 Bae, S., Bessho, Y., Hojo, M. \& Kageyama, R. The bHLH gene Hes6, an inhibitor of Hes1, promotes neuronal differentiation. Development 127, 2933-2943 (2000).

41 Baladron, V. et al. dlk acts as a negative regulator of Notch1 activation through interactions with specific EGF-like repeats. Exp Cell Res 303, 343-359, doi:10.1016/j.yexcr.2004.10.001 (2005).

42 Bray, S. J., Takada, S., Harrison, E., Shen, S. C. \& Ferguson-Smith, A. C. The atypical mammalian ligand Delta-like homologue 1 (Dlk1) can regulate Notch signalling in Drosophila. BMC Dev Biol 8, 11, doi:10.1186/1471-213X-8-11 (2008).

43 Ladi, E. et al. The divergent DSL ligand DII3 does not activate Notch signaling but cell autonomously attenuates signaling induced by other DSL ligands. I Cell Biol 170, 983-992, doi:10.1083/jcb.200503113 (2005).

44 Nueda, M. L., Baladron, V., Sanchez-Solana, B., Ballesteros, M. A. \& Laborda, J. The EGF-like protein dlk1 inhibits notch signaling and potentiates adipogenesis of mesenchymal cells. J Mol Biol 367, 1281-1293, doi:10.1016/j.jmb.2006.10.043 (2007).

45 Tsarovina, K., Schellenberger, J., Schneider, C. \& Rohrer, H. Progenitor cell maintenance and neurogenesis in sympathetic ganglia involves Notch signaling. Mol Cell Neurosci 37, 20-31, doi:10.1016/j.mcn.2007.08.010 (2008).

46 Takashima, Y. et al. Neuroepithelial cells supply an initial transient wave of MSC differentiation. Cell 129, 1377-1388, doi:10.1016/j.cell.2007.04.028 (2007).

47 Kuronuma, K. et al. Matrix Gla protein maintains normal and malignant hematopoietic progenitor cells by interacting with bone morphogenetic protein-4. Heliyon 6, e03743, doi:10.1016/j.heliyon.2020.e03743 (2020).

48 Celebi, B., Mantovani, D. \& Pineault, N. Insulin-like growth factor binding protein-2 and neurotrophin 3 synergize together to promote the expansion of hematopoietic cells ex vivo. Cytokine 58, 327-331, doi:10.1016/j.cyto.2012.02.011 (2012).

49 Klamer, S. E. et al. TGFBI Expressed by Bone Marrow Niche Cells and Hematopoietic Stem and Progenitor Cells Regulates Hematopoiesis. Stem Cells Dev 27, 1494-1506, doi:10.1089/scd.2018.0124 (2018).

50 Barrett, N. A. et al. MIl-AF4 Confers Enhanced Self-Renewal and Lymphoid Potential during a Restricted Window in Development. Cell Rep 16, 1039-1054, doi:10.1016/j.celrep.2016.06.046 (2016).

51 Spiegel, A. et al. Catecholaminergic neurotransmitters regulate migration and repopulation of immature human CD34+ cells through Wnt signaling. Nat Immunol 8, 1123-1131, doi:10.1038/ni1509 (2007).

52 Mendez-Ferrer, S., Lucas, D., Battista, M. \& Frenette, P. S. Haematopoietic stem cell release is regulated by circadian oscillations. Nature 452, 442-447, doi:10.1038/nature06685 (2008).

53 Kobayashi, K. et al. Targeted disruption of the tyrosine hydroxylase locus results in severe catecholamine depletion and perinatal lethality in mice. J Biol Chem 270, 27235-27243 (1995).

54 Zhou, Q. Y., Quaife, C. J. \& Palmiter, R. D. Targeted disruption of the tyrosine hydroxylase gene reveals that catecholamines are required for mouse fetal development. Nature 374, 640-643, doi:10.1038/374640a0 (1995).

55 Zhang, P. et al. Altered cell differentiation and proliferation in mice lacking p57KIP2 indicates a role in Beckwith-Wiedemann syndrome. Nature 387, 151-158, doi:10.1038/387151a0 (1997).

56 Gama-Norton, L. et al. Notch signal strength controls cell fate in the haemogenic endothelium. Nature communications 6, 8510, doi:10.1038/ncomms9510 (2015). 
57 Lizama, C. O. et al. Repression of arterial genes in hemogenic endothelium is sufficient for haematopoietic fate acquisition. Nature communications 6, 7739, doi:10.1038/ncomms8739 (2015).

58 Souilhol, C. et al. Developing HSCs become Notch independent by the end of maturation in the AGM region. Blood 128, 1567-1577, doi:10.1182/blood-2016-03-708164 (2016).

59 Isern, J. et al. The neural crest is a source of mesenchymal stem cells with specialized hematopoietic stem cell niche function. Elife 3, e03696, doi:10.7554/eLife.03696 (2014).

60 Morikawa, S. et al. Development of mesenchymal stem cells partially originate from the neural crest. Biochem Biophys Res Commun 379, 1114-1119, doi:10.1016/j.bbrc.2009.01.031 (2009).

61 Nagoshi, N. et al. Ontogeny and multipotency of neural crest-derived stem cells in mouse bone marrow, dorsal root ganglia, and whisker pad. Cell stem cell 2, 392-403, doi:10.1016/j.stem.2008.03.005 (2008).

62 Damm, E. W. \& Clements, W. K. Pdgf signalling guides neural crest contribution to the haematopoietic stem cell specification niche. Nat Cell Biol 19, 457-467, doi:10.1038/ncb3508 (2017).

63 Saito, D. \& Takahashi, Y. Sympatho-adrenal morphogenesis regulated by the dorsal aorta. Mech Dev 138 Pt 1, 2-7, doi:10.1016/j.mod.2015.07.011 (2015).

64 Chen, S. R., Zheng, Q. S., Zhang, Y., Gao, F. \& Liu, Y. X. Disruption of genital ridge development causes aberrant primordial germ cell proliferation but does not affect their directional migration. BMC Biol 11, 22, doi:10.1186/1741-7007-11-22 (2013).

65 Picelli, S. et al. Full-length RNA-seq from single cells using Smart-seq2. Nature protocols 9, 171-181, doi:10.1038/nprot.2014.006 (2014).

66 Dobin, A. et al. STAR: ultrafast universal RNA-seq aligner. Bioinformatics 29, 15-21, doi:10.1093/bioinformatics/bts635 (2013).

67 Bray, N. L., Pimentel, H., Melsted, P. \& Pachter, L. Near-optimal probabilistic RNA-seq quantification. Nat Biotechnol 34, 525-527, doi:10.1038/nbt.3519 (2016).

68 Ewels, P., Magnusson, M., Lundin, S. \& Kaller, M. MultiQC: summarize analysis results for multiple tools and samples in a single report. Bioinformatics 32, 3047-3048, doi:10.1093/bioinformatics/btw354 (2016).

69 Martin, M. Cutadapt removes adapter sequences from high-throughput sequencing reads. EMBnet.journal 17, 10-12 (2011).

70 Lun, A. T., McCarthy, D. J. \& Marioni, J. C. A step-by-step workflow for low-level analysis of single-cell RNA-seq data with Bioconductor. F1000Res 5, 2122, doi:10.12688/f1000research.9501.2 (2016).

71 McCarthy, D. J., Campbell, K. R., Lun, A. T. \& Wills, Q. F. Scater: pre-processing, quality control, normalization and visualization of single-cell RNA-seq data in R. Bioinformatics 33, 1179-1186, doi:10.1093/bioinformatics/btw777 (2017).

72 Scialdone, A. et al. Computational assignment of cell-cycle stage from single-cell transcriptome data. Methods 85, 54-61, doi:10.1016/j.ymeth.2015.06.021 (2015).

73 Ritchie, M. E. et al. limma powers differential expression analyses for RNA-sequencing and microarray studies. Nucleic Acids Res 43, e47, doi:10.1093/nar/gkv007 (2015).

74 van der Maaten, L. \& Hinton, G. Visualizing data using t-SNE. J Mach Learn Res 9, 2579-2605 (2008).

75 Robinson, M. D., McCarthy, D. J. \& Smyth, G. K. edgeR: a Bioconductor package for differential expression analysis of digital gene expression data. Bioinformatics 26, 139-140, doi:10.1093/bioinformatics/btp616 (2010).

76 Street, K. et al. Slingshot: cell lineage and pseudotime inference for single-cell transcriptomics. BMC Genomics 19, 477, doi:10.1186/s12864-018-4772-0 (2018).

77 Subramanian, A. et al. Gene set enrichment analysis: a knowledge-based approach for interpreting genome-wide expression profiles. Proceedings of the National Academy of 
bioRxiv preprint doi: https://doi.org/10.1101/2021.09.13.459835; this version posted September 13, 2021. The copyright holder for this preprint (which was not certified by peer review) is the author/funder, who has granted bioRxiv a license to display the preprint in perpetuity. It is made available under aCC-BY 4.0 International license.

836

837

838

839

840

841

842

843

Sciences of the United States of America 102, 15545-15550, doi:10.1073/pnas.0506580102 (2005).

78 Kamburov, A., Stelzl, U., Lehrach, H. \& Herwig, R. The ConsensusPathDB interaction database: 2013 update. Nucleic Acids Res 41, D793-800, doi:10.1093/nar/gks1055 (2013).

79 Edgar, R., Domrachev, M. \& Lash, A. E. Gene Expression Omnibus: NCBI gene expression and hybridization array data repository. Nucleic Acids Res 30, 207-210, doi:10.1093/nar/30.1.207 (2002). 
844

845

846

847

848

849

850

851

852

853

854

855

856

857

858

859

860

861

862

863

864

865

866

867

868

869

870

871

872

873

874

875

876

877

\section{FIGURE LEGENDS}

Figure 1: p57Kip2 deletion expands HSC numbers in the AGM and the early fetal liver.

Single cell preparations of (A) E11 AGM (0.5-1 embryo equivalent [ee]), (B) E12 AGM (1ee), (C) E11 FL (1ee), (D) E12 FL (0.05ee), (E) E11 placenta (PL, 2ee), (F) E12 PL (1ee), (G) E11 yolk sac (YS, 2ee) and (H) E12 YS (1ee) from wild-type (WT) and p57Kip2-null (KO) embryos were transplanted into irradiated recipients and donor chimerism determined after 4 months by flow cytometry. Data points represent individual recipients with the number of repopulated $>5 \%$ chimerism as indicated by the dashed line) recipients/total recipients indicated underneath each graph together with the percentage of repopulated mice. Solid line represents mean; * $p<0.05,{ }^{* *} p<0.01$, Mann-Whitney $U$ test. (I) In situ hybridisation with a p57Kip2 riboprobe on transverse cryosections of E11 placenta showing high expression of $p 57$ Kip2 in trophoblast cells of the placental labyrinth.

\section{Figure 2: p57Kip2 is highly expressed in the sympathetic nervous system.}

Immunohistochemistry on cryosections from E11 wild-type embryos. (A) Immunostaining for p57Kip2 (red) and CD34 (green) with DAPI nuclear stain (blue). P57Kip2 expression is highlighted in endothelial cells (arrowheads), sub-endothelial mesenchyme (asterisk) and SA cells (arrows). (B) Immunostaining for p57Kip2 (red) and Ngfr (green) with DAPI nuclear stain (blue). P57Kip2 expression is highlighted in sub-endothelial mesenchyme (asterisk) and SA cells (arrows). Dashed line shows outline of the aorta. (C) Immunostaining for Pdgfr $\beta$ (red) with DAPI nuclear stain (blue). Exclusion of Pdgfr $\beta$ expression from SA cells is highlighted (arrows). Scale bars indicate $50 \mu \mathrm{m}$. (D) Sorting strategy for AGM subpopulations; HSPCs, CD34+CD45+; endothelial cells (EC), CD34+CD45-; SA cells, Ngfr+Pdgfr $\beta-$; mesenchymal cells (ME), Ngfr-Pdgfr $\beta+$. Gating was based on fluorescence minus one controls (FMOs) as shown in Figure S1. (E, F) p57Kip2 mRNA expression (relative to $\beta$ actin) by $\mathrm{qPCR}$ in subpopulations sorted from E11 and E12 AGMs. $\mathrm{n} \geq 3$. Histogram represents mean \pm SEM.

Figure 3: p57Kip2 increases HSC numbers through an expansion of the catecholamine-secreting SA compartment.

(A) Immunostaining for Th (red) with DAPI nuclear stain (blue) on cryosections from E11 p57Kip2 wild-type (WT) and knockout (KO) embryos. Dashed line shows outline of the aorta. Scale bars indicate $50 \mu \mathrm{m}$. (B) Percentage of Ngfr+ SA cells from E11 p57Kip2 wild-type (WT) and knockout (KO) embryos in the different cell cycle stages. DAPI-stained Ngfr+ E11 AGM cells were analysed by flow cytometry. (C, D) Quantification of the catecholamines noradrenaline (C) and dopamine (D) by HPLC in individual p57Kip2 wild-type and knockout E11 and E12 AGMs. Concentration is measured in 
femtomole per embryo equivalent (ee). Black lines denote the mean, $n=14 .{ }^{*} p<0.05,{ }^{* *} p<0.01$, two-tailed, unpaired $t$-test. (E, F) Donor chimerism in recipients of AGM cells from E11 or E12 p57Kip2 wild-type (WT) or knockout (KO) embryos treated in utero with the $\alpha$ adrenergic receptor (Adra1 and Adra2) blocker phentolamine (E) or the $\beta$ adrenergic receptor blocker propranolol (F). (G) Donor chimerism in recipients of AGM cells from E11 or E12 p57Kip2 wild-type (WT) embryos treated in utero with specific $\beta$ adrenergic receptor blockers betaxolol (for Adrb1), ICI 118,551 (for Adrb2) and SR 59230A (for Adrb3). (H) Donor chimerism in recipients of AGM cells from E11 or E12 p57Kip2 knockout (KO) embryos treated in utero with the Adrb2 blocker ICl 118,551. Data points represent chimerism in individual recipients determined by flow cytometry after 4 months, with the dashed line indicating 5\% threshold and the solid line the mean. (I) Frequency of embryos with the indicated genotypes (E11-12).

\section{Figure 4: p57Kip2 is expressed in sympathoadrenal progenitor cells.}

(A) Schematic depiction of maturation stages in the SA lineage as defined by listed marker expression. Underlined markers were used in immunohistochemistry in (B). (B) Immunohistochemical staining of E11 wild-type embryo cryosections for p57Kip2 (red), Sox (green), Phox2b (green), Gata3 (green) and Th (white), with DAPI as nuclear counterstain (blue). Close-ups of boxed areas in merged images are shown. White scale bars equal $10 \mu \mathrm{m}$ and red bars equal $100 \mu \mathrm{m}$.

\section{Figure 5: Single-cell RNA-Seq reveals neural crest differentiation pathways.}

(A) Immunohistochemical staining of E11 wild-type embryo cryosection for Ngfr (green), p57Kip2 (red) and Th (white). Bar represents ventral vs dorsal subdissection. (B) t-SNE plots coloured for clusters identified by k-means clustering (left) and for ventral and dorsal origin (right). Violin plots for expression levels of $\mathrm{Ngfr}$ (C) and haematopoiesis-associated genes Ptprc/CD45 (D), Csf1r (E), Cx3cr1 (F), Runx1 (G), Procr/EPCR (H), Kit (I) and Cd34 (J). (K) t-SNE coloured for predicted cell cycle phases (top) and the identified clusters before (middle) and after (bottom) cell cycle correction. (L) t-SNE plot of remaining 4 clusters following cell cycle correction (bottom) and coloured according to ventral and dorsal origin (top). t-SNE gene expression plots coloured for expression levels of SNS genes Sox10 (M), Th (N), Phox2a (O), Gata3 (P), Phox2b (Q) and Cdkn1c/p57Kip2 (R).

\section{Figure 6: Notch signalling is downregulated upon SA maturation.}

(A) t-SNE plot of 4 clusters with slingshot-identified lineage trajectory nodes superimposed. $t-S N E$ gene expression plot coloured for expression levels of $\mathrm{Ngfr}$ (B). Pseudotime plots for SNS differentiation markers Sox10 (C), Th (D), Phox2a (E), Gata3 (F), Phox2b (G) and Cdkn1c/p57Kip2 (H). 
t-SNE gene expression plots coloured for expression levels Notch pathway-associated genes Notch1

Figure 7: Neural crest cells can take an alternative differentiation path towards a mesenchymal fate upon arrival at the aorta.

t-SNE plots coloured for the expression levels of mesenchymal genes Bmper (A) and Pdgfra (B). (C) t-

SNE plot of Ngfr+ cells with Pdgfra+Ngfr- mesenchymal cells sorted from the ventral E11 AGM. (D) upregulated in ventrally derived Ngfr1+ cells.

\section{SUPPLEMENTAL FIGURE LEGENDS}

Figure S1

Sorting gates and fluorescence-minus one (FMO) controls for isolating endothelial cells (EC), haematopoietic stem and progenitor cells (HSPC), sympathoadrenal cells (SA) and mesenchymal cells (ME) from the AGM.

\section{Figure S2}

(A) Real-time PCR analysis of Gata3 and Th expression in E11 wild-type (WT) and p57Kip2 knockout (KO) AGMs. Th expression by real-time PCR in the AGM, foetal liver (FL), yolk sac (YS) and placenta (Pla) from E11 (B) and E12 (C) wild-type embryos. (D) Analysis of catecholamine levels by HPLC in the adult bone marrow (BM), AGM, FL, YS and Pla.

\section{Figure S3}

939 Heatmaps showing the top 40 differentially expressed genes in the macrophage cluster 3 before cell 940 cycle adjustment (A) and, after cell cycle adjustments, in the remaining four clusters (B-G).

943 Heatmaps showing the top 40 differentially expressed genes in the two alternative differentiation pathways of neural crest cells. 
bioRxiv preprint doi: https://doi.org/10.1101/2021.09.13.459835; this version posted September 13,2021 . The copyright holder for this preprint (which was not certified by peer review) is the author/funder, who has granted bioRxiv a license to display the preprint in perpetuity. It is made available under aCC-BY 4.0 International license.

946

947 
A

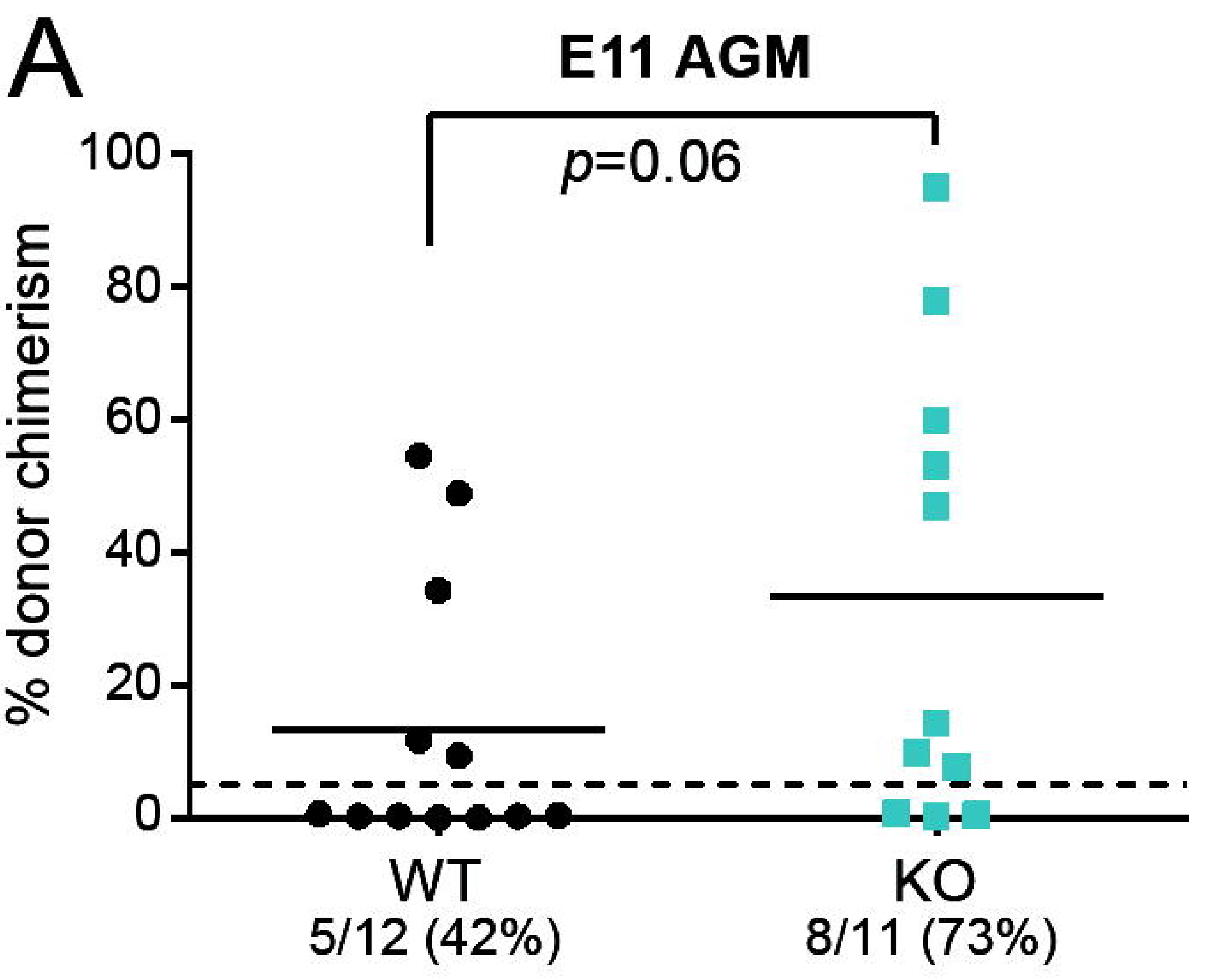

C

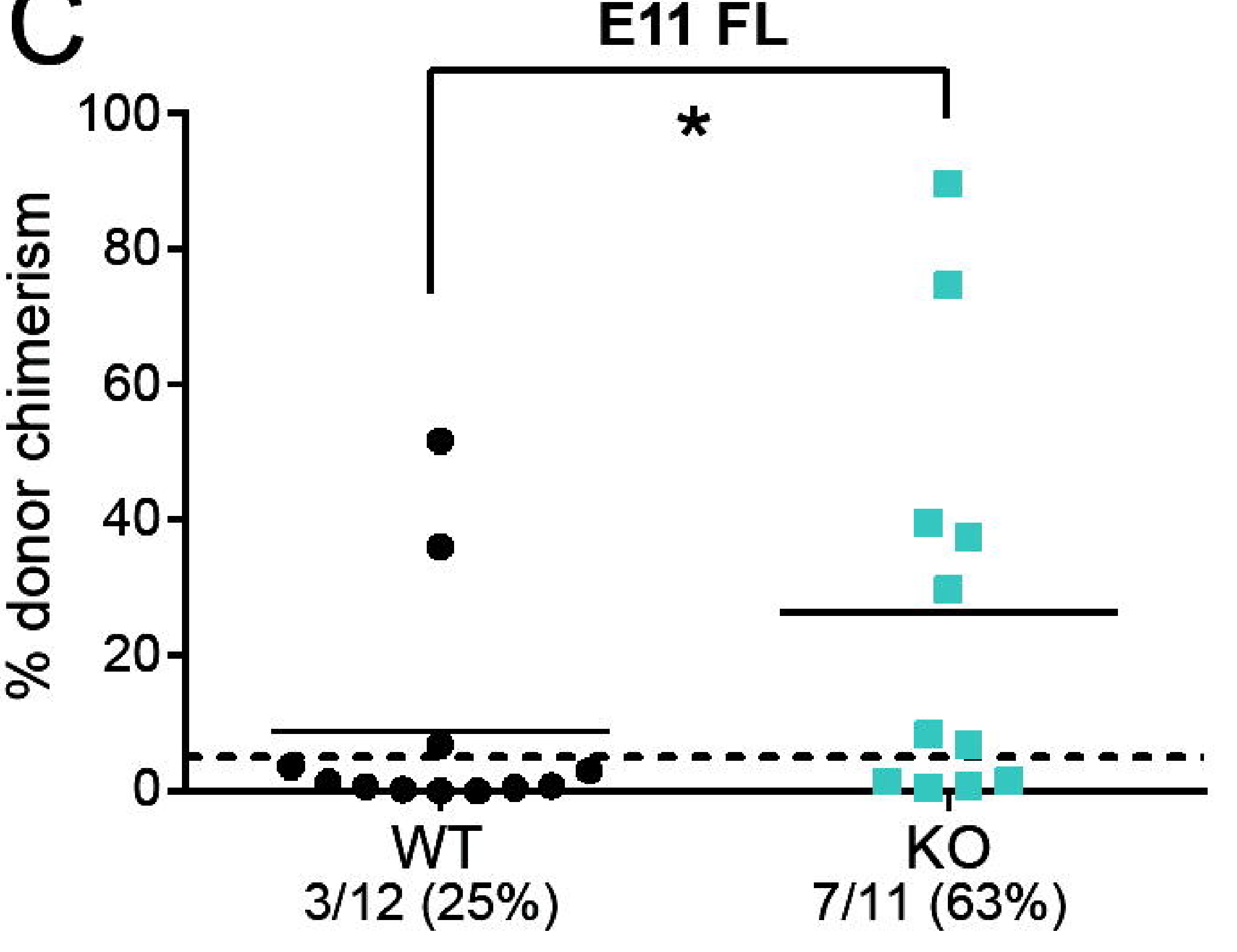

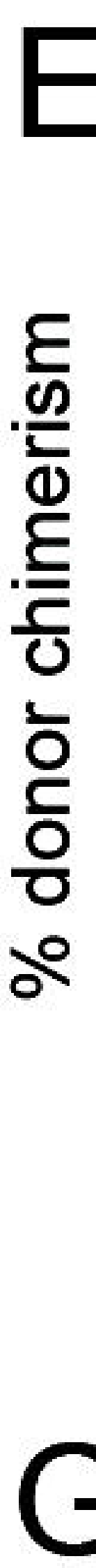

E11 PL

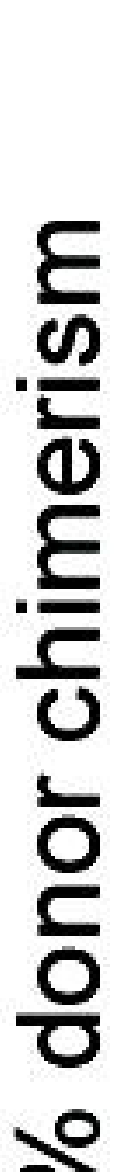

B

E12 AGM

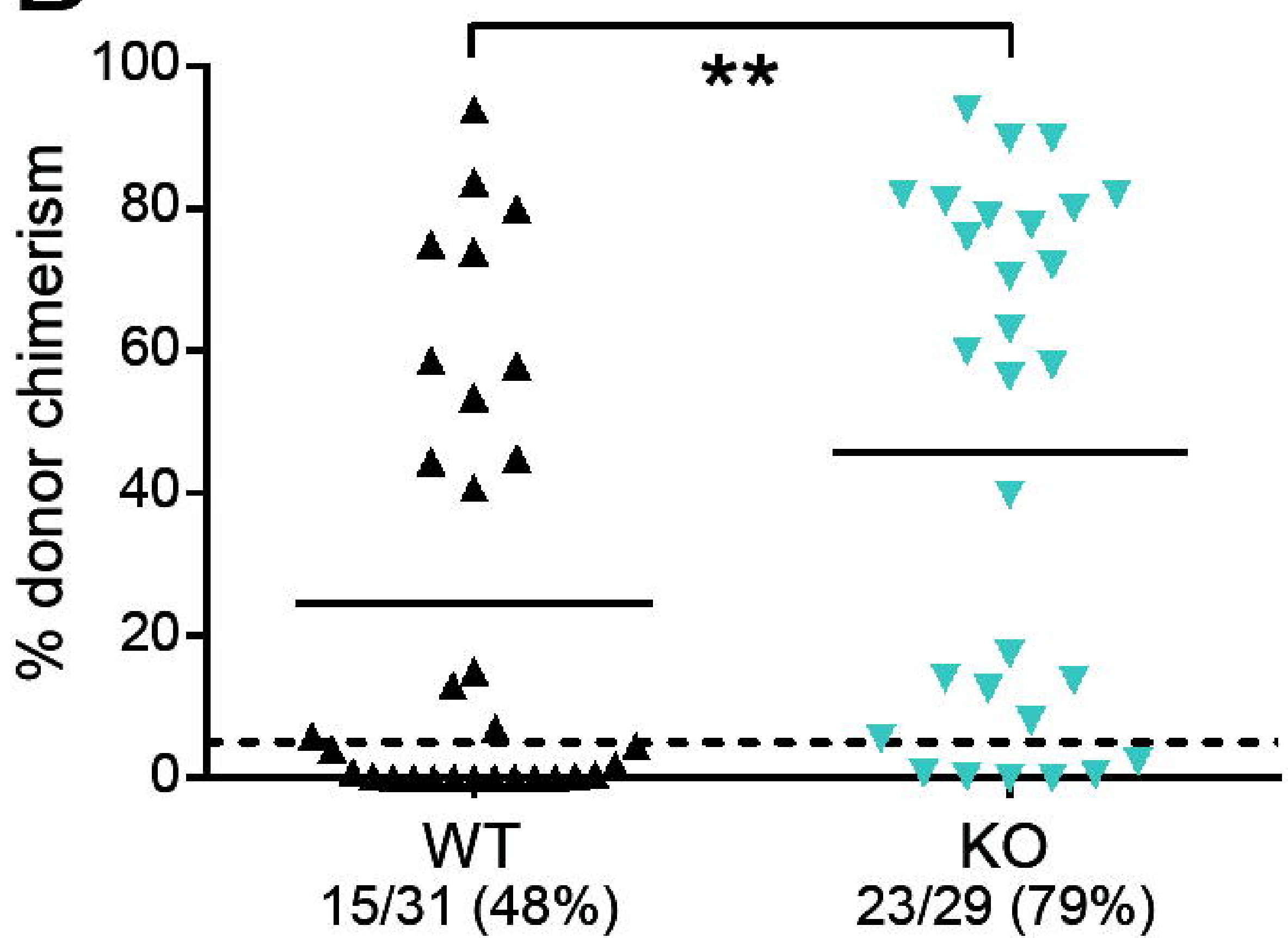

E12 FL
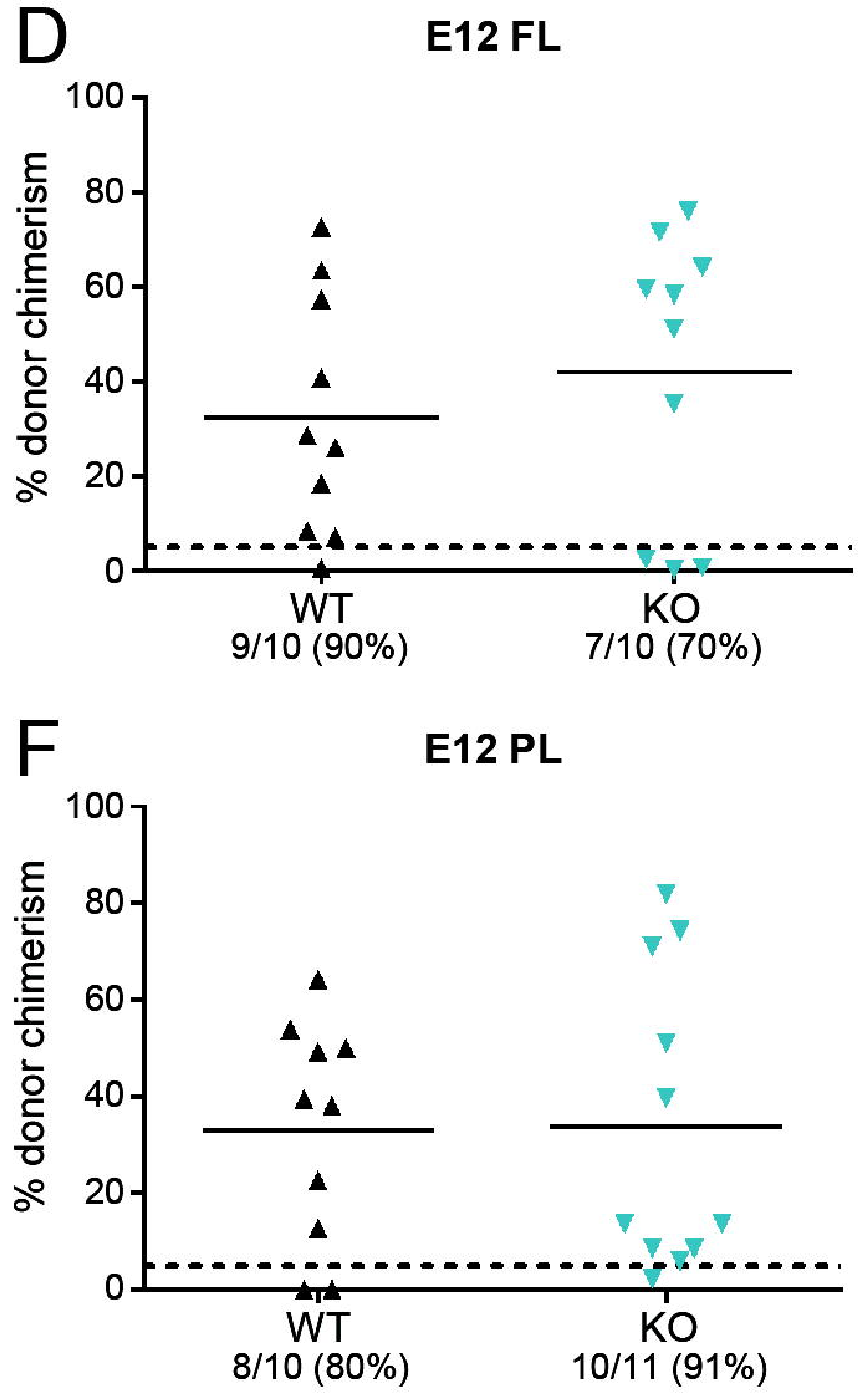

$\mathrm{H}$

E12 YS

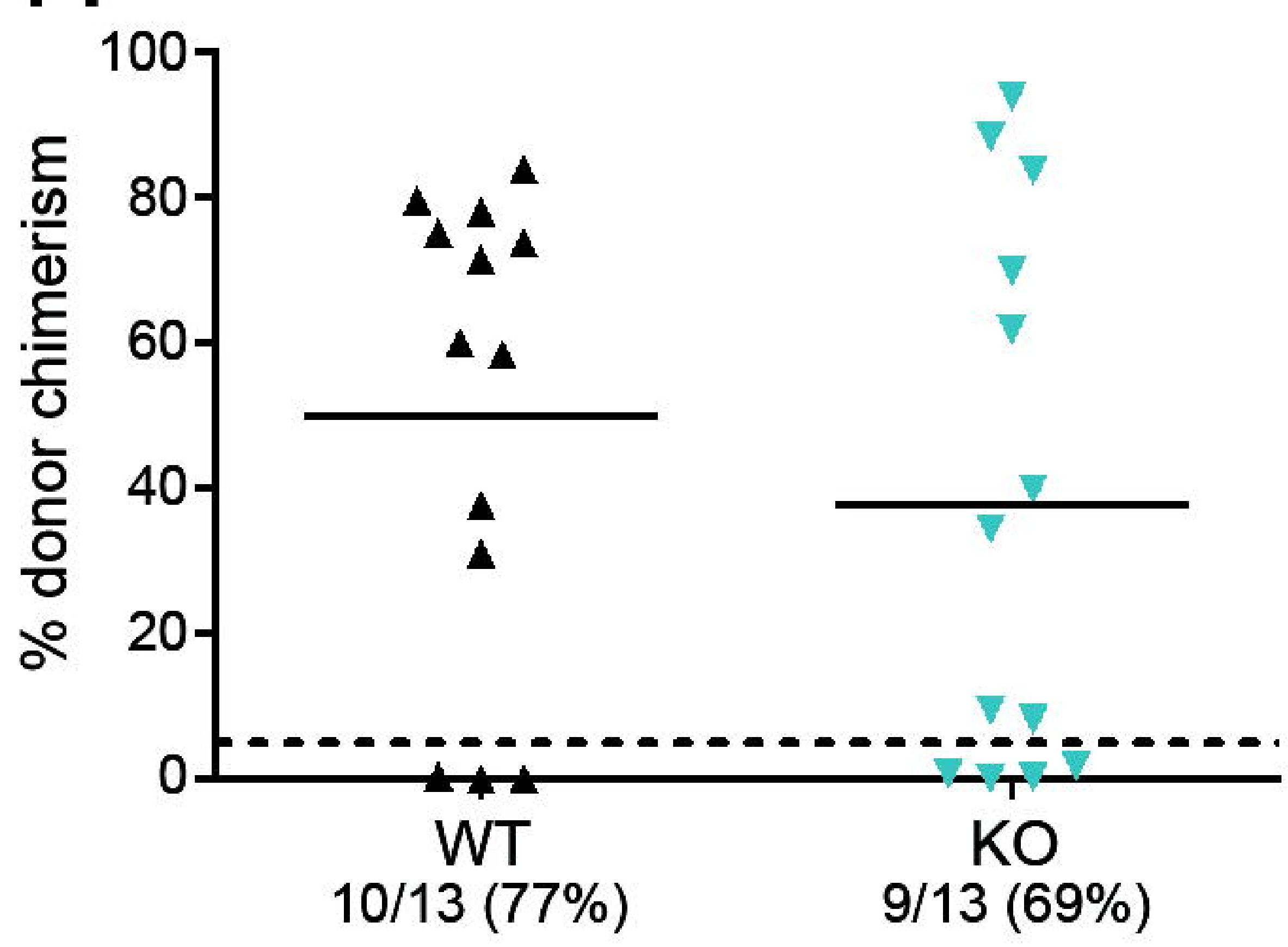

Figure 1 
A
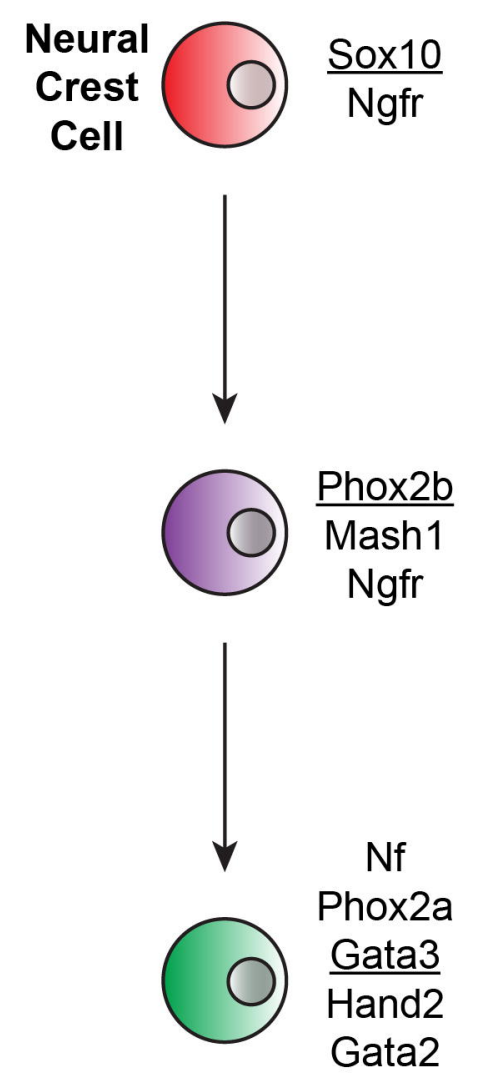

Ngfr
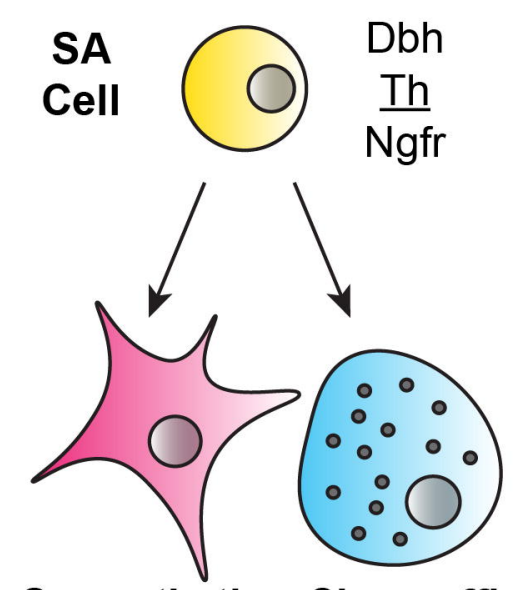

Sympathetic Chromaffin Neuron

Cell
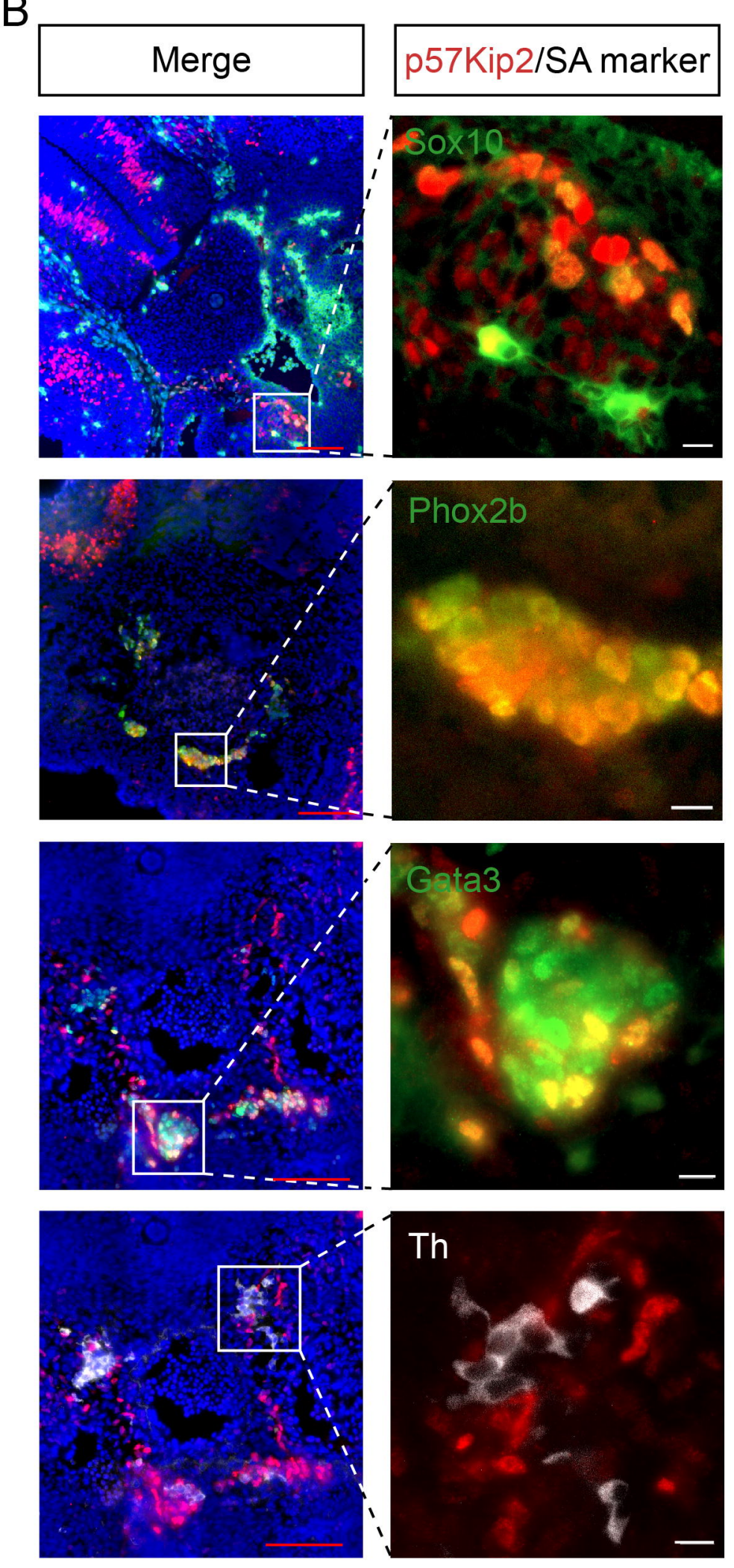
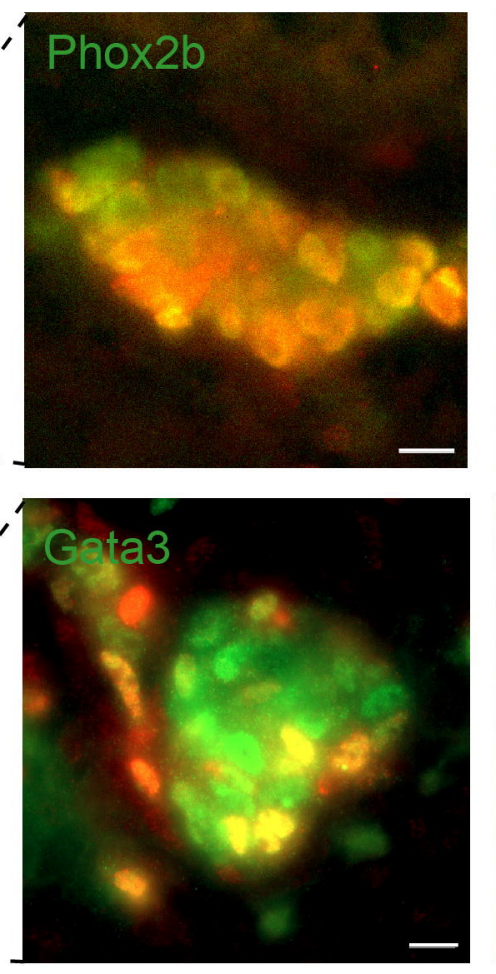

SA marker/DAPI
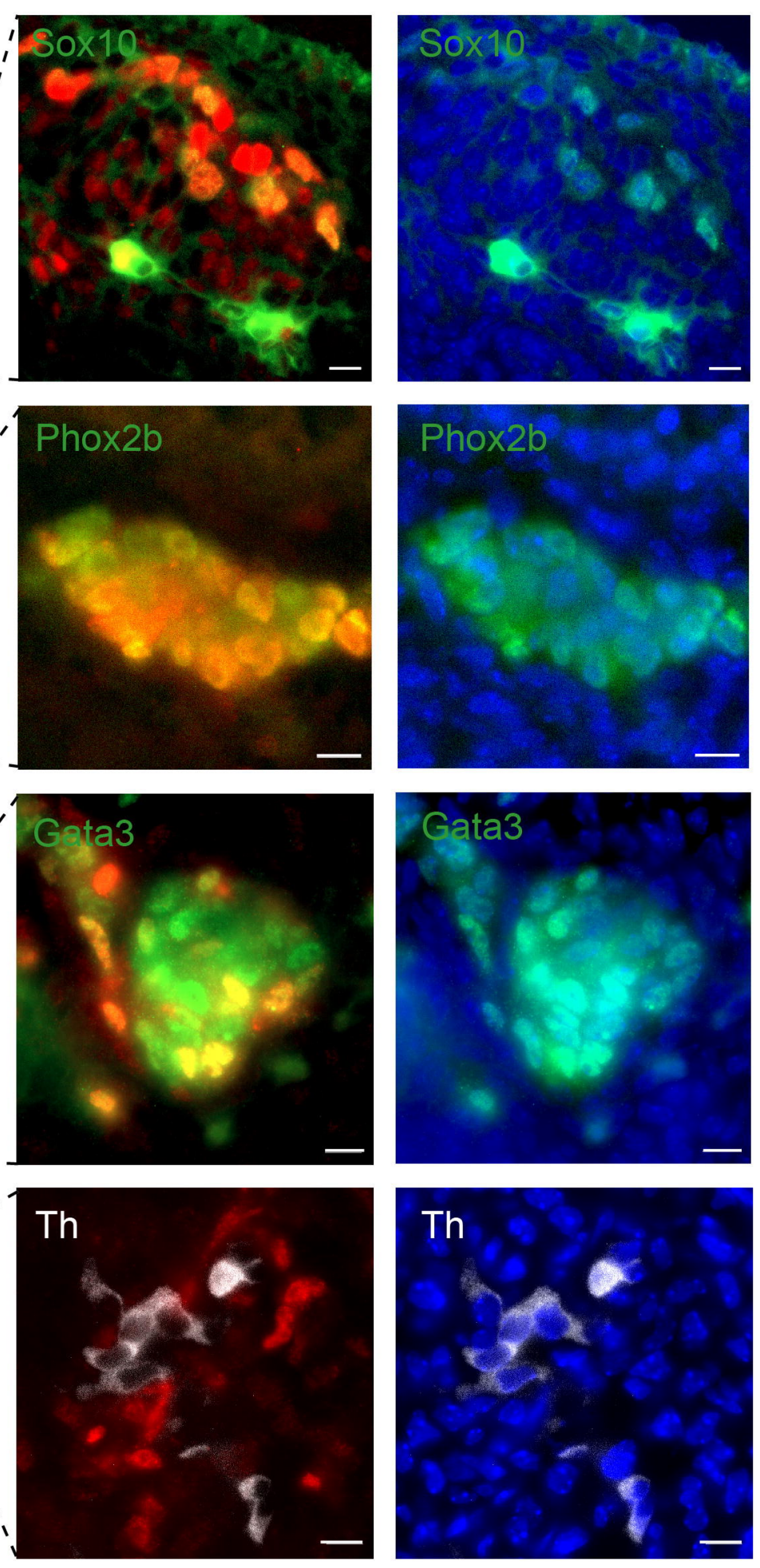

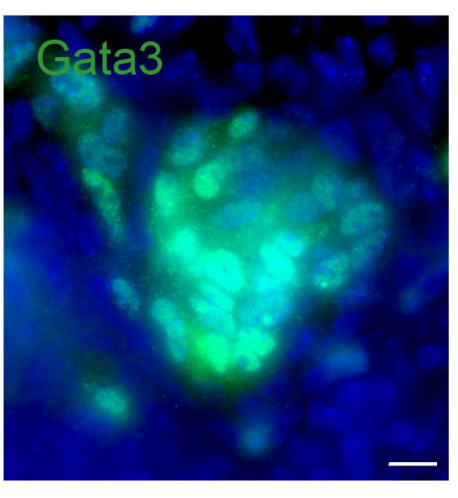

Th

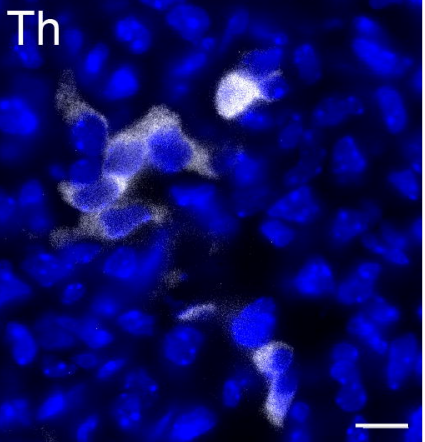

\section{p57Kip2/DAPI}
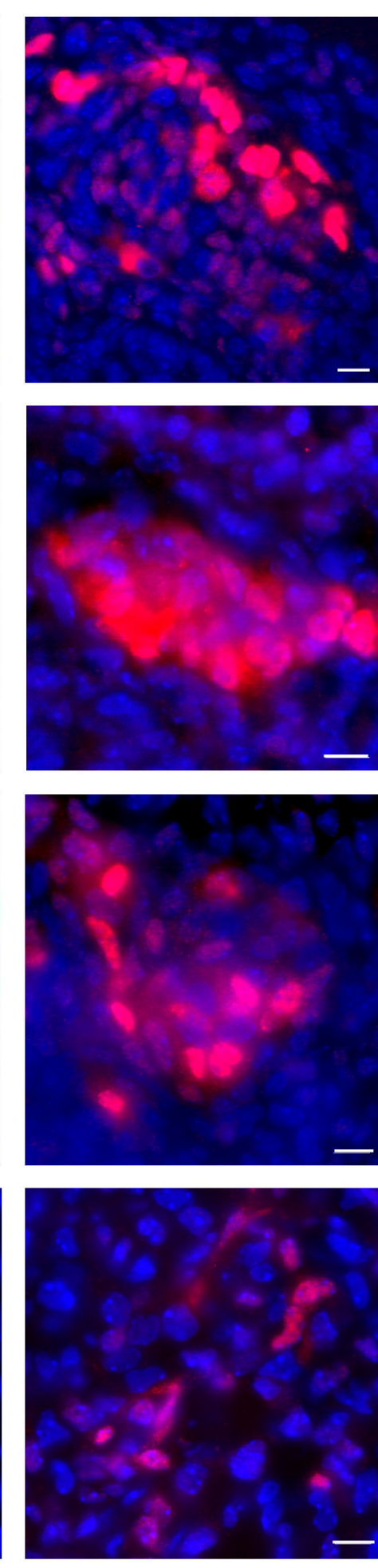

Figure 4 
$A$

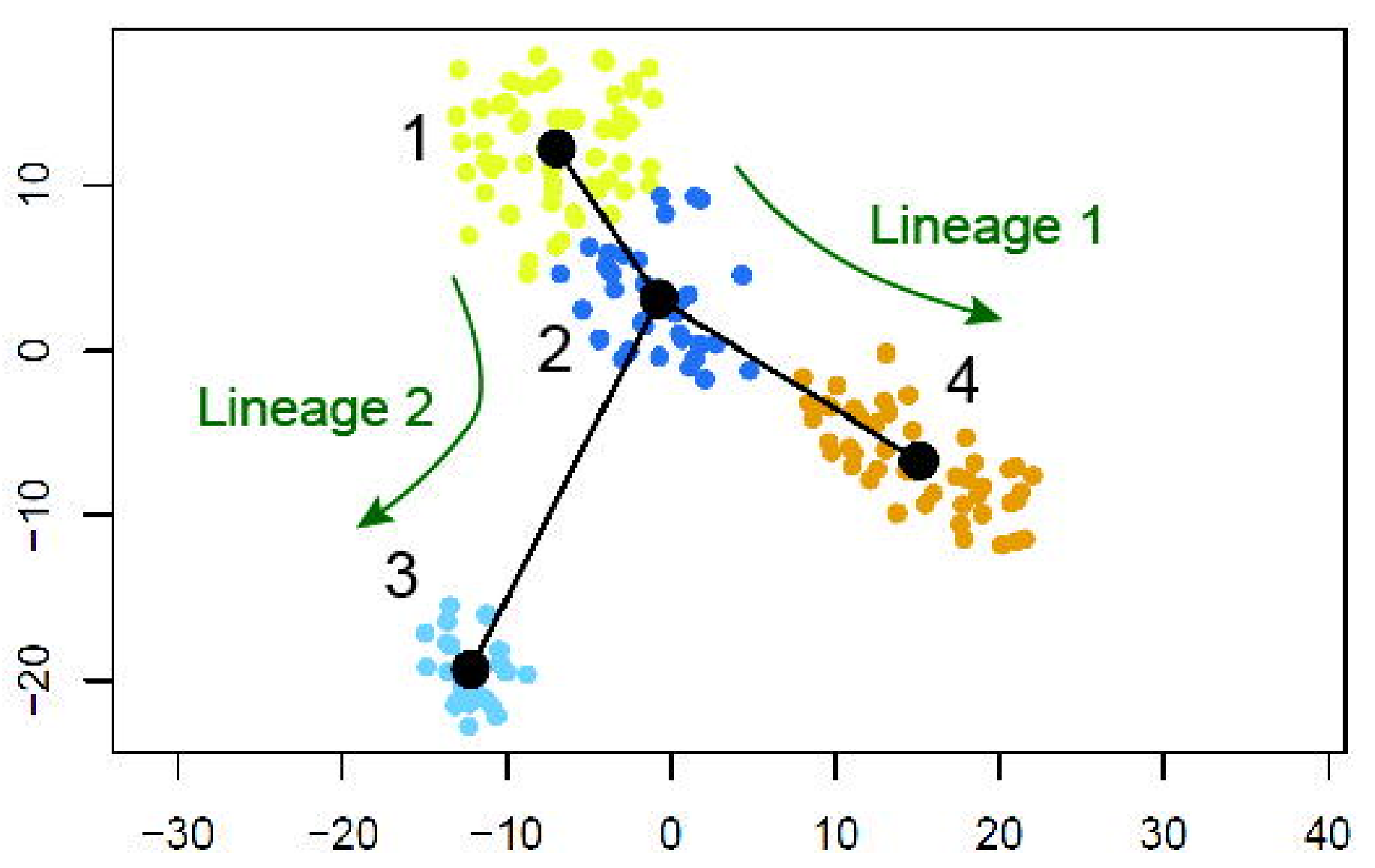

TSNE 1

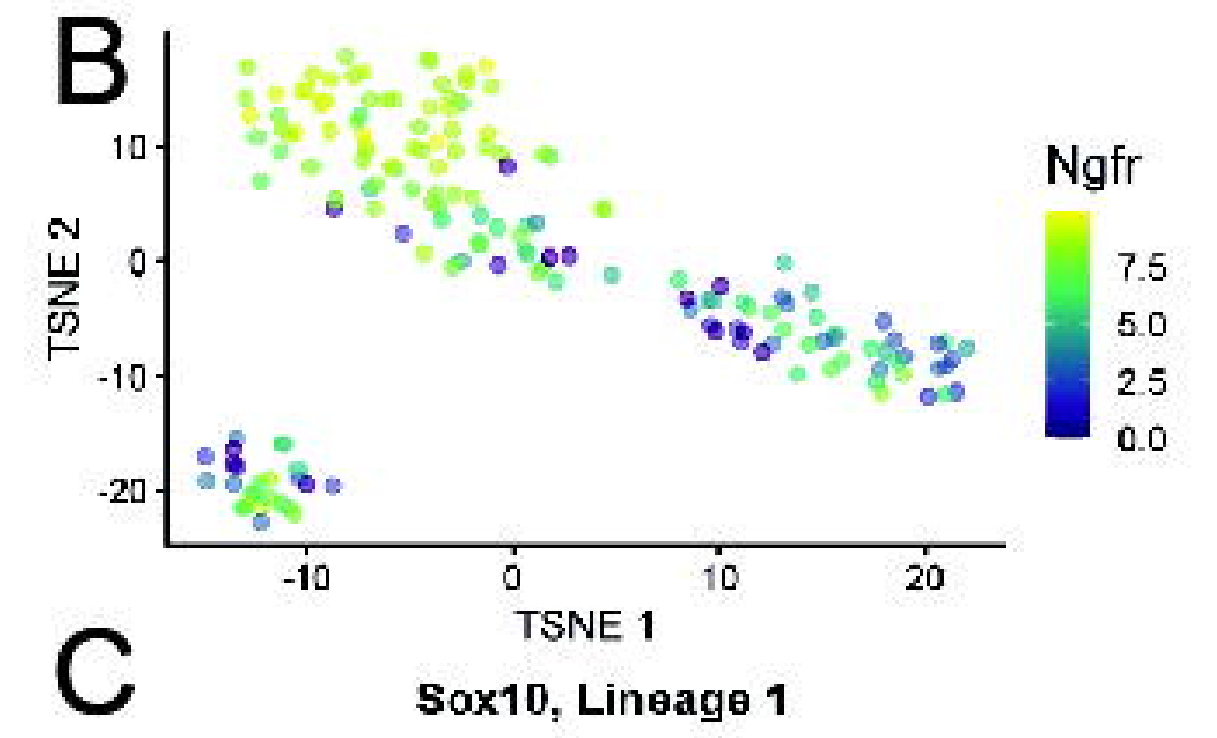

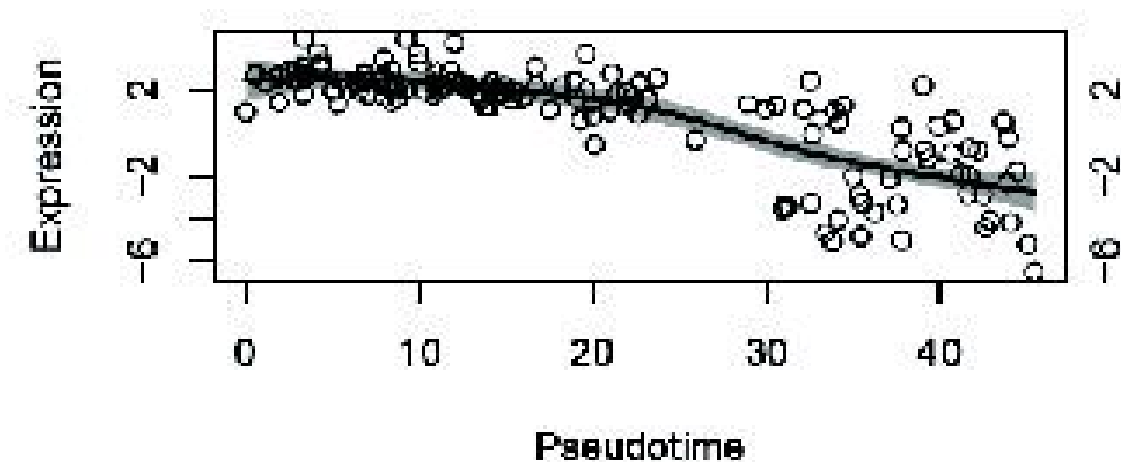

E

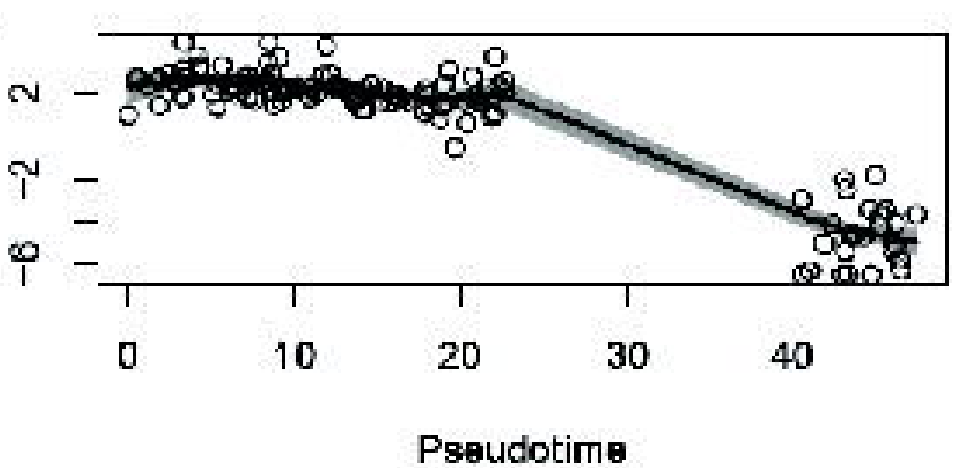

Th, Lineage 2

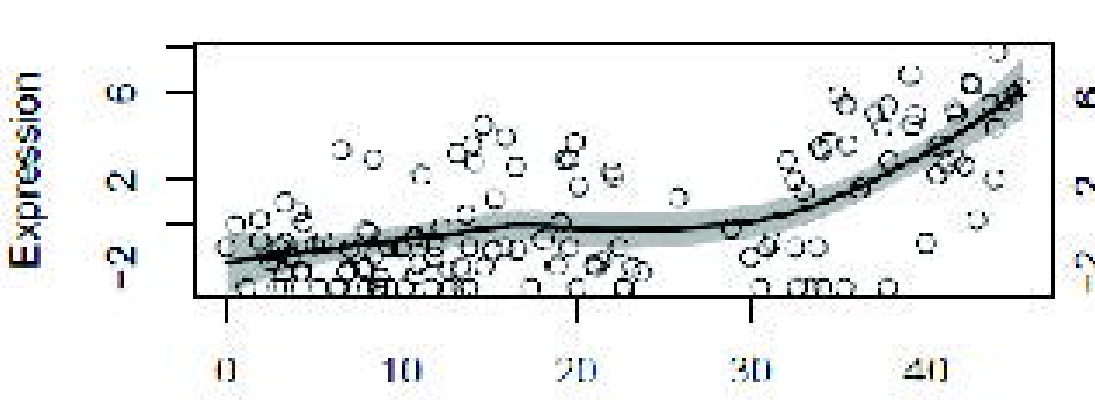

Gata3, Lineage 1

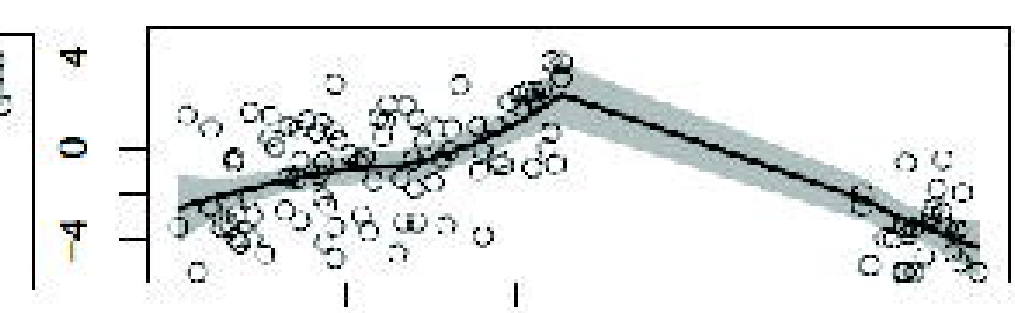

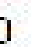

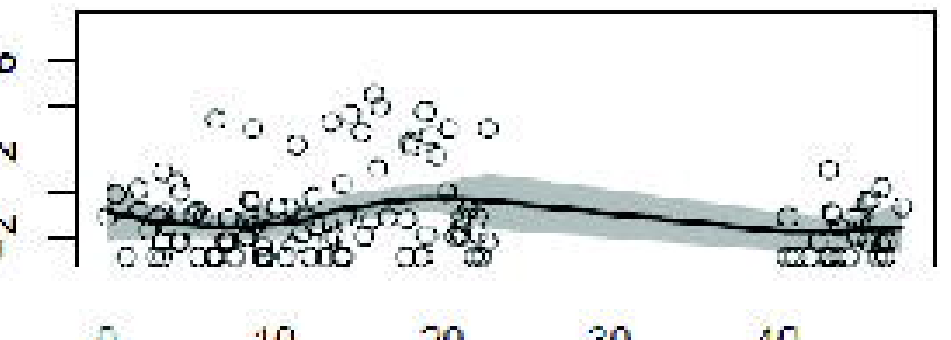

$\begin{array}{llll}10 & 20 & 30 & 40\end{array}$

$\mathrm{F}$

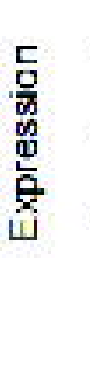

$\mathrm{H}$

Cdkn1c, Lineage 2

\section{总}

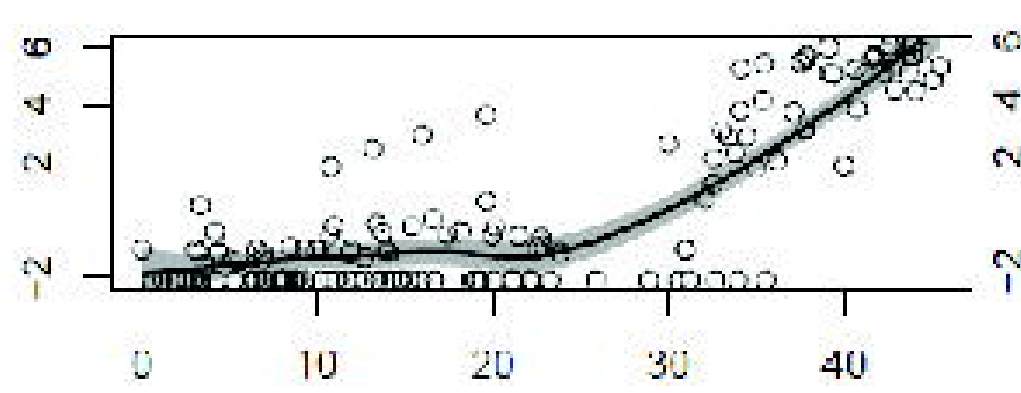

G

Phox 2b, Lineage 1

Phox2b, Lineage 2
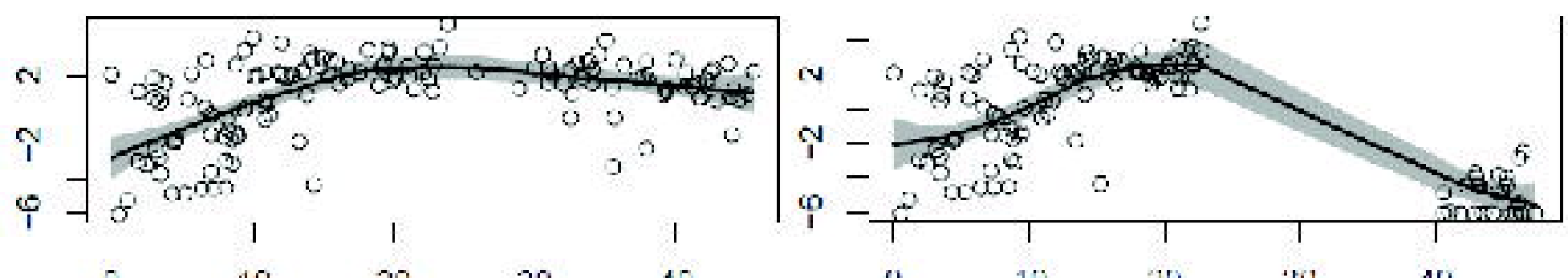

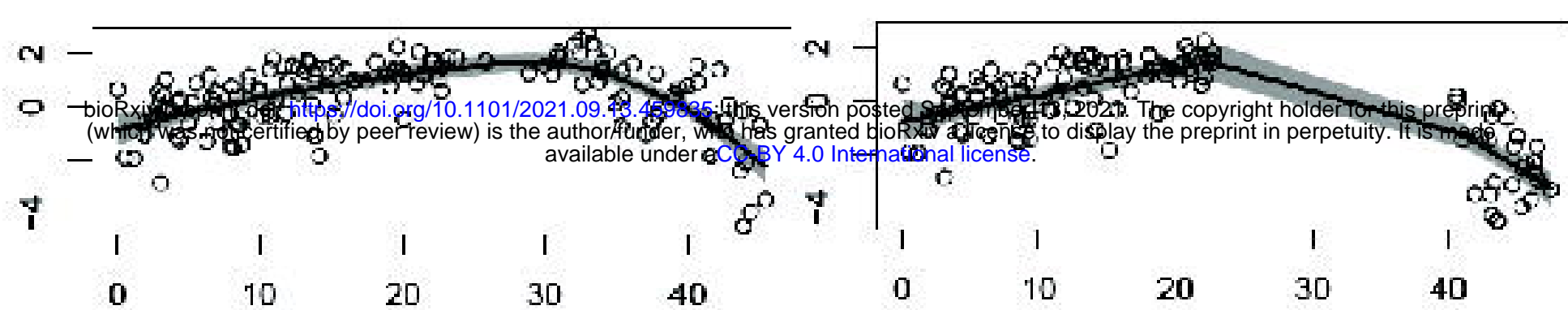

I'seudolime

I seudolme
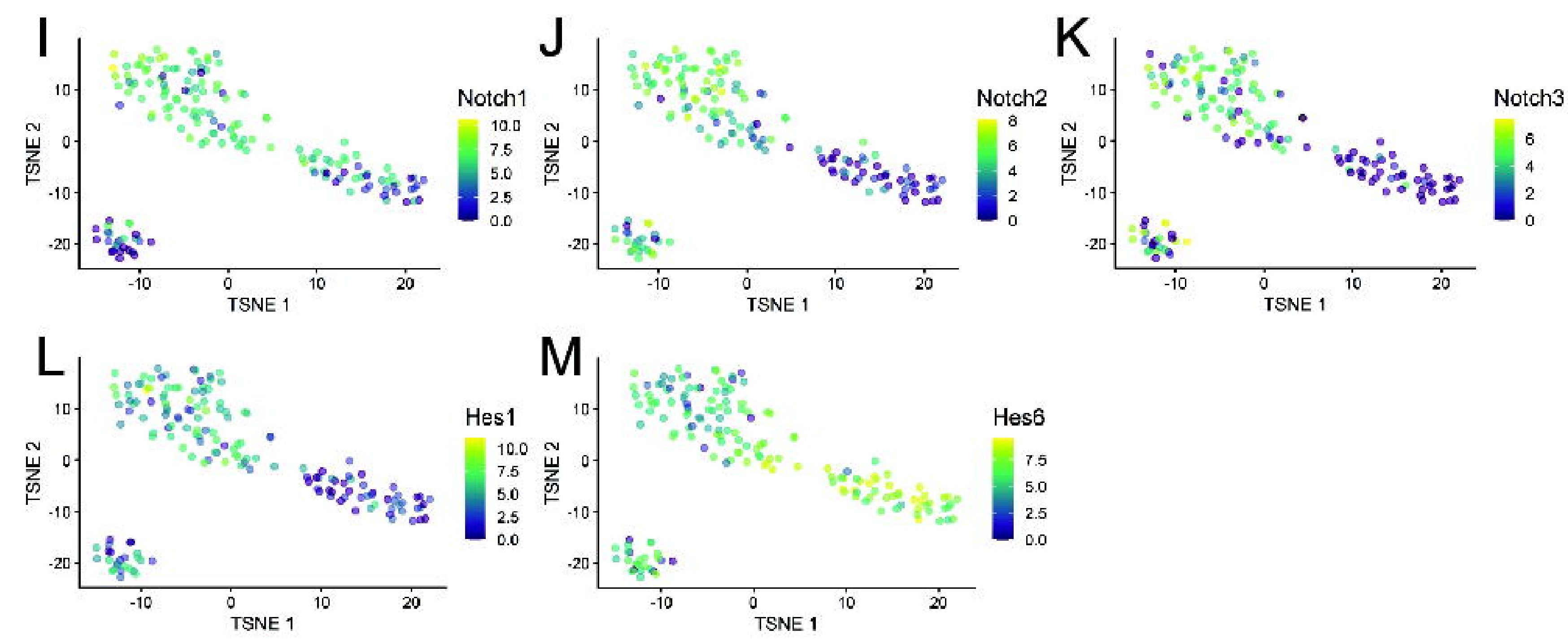

\section{$\mathrm{N}$}
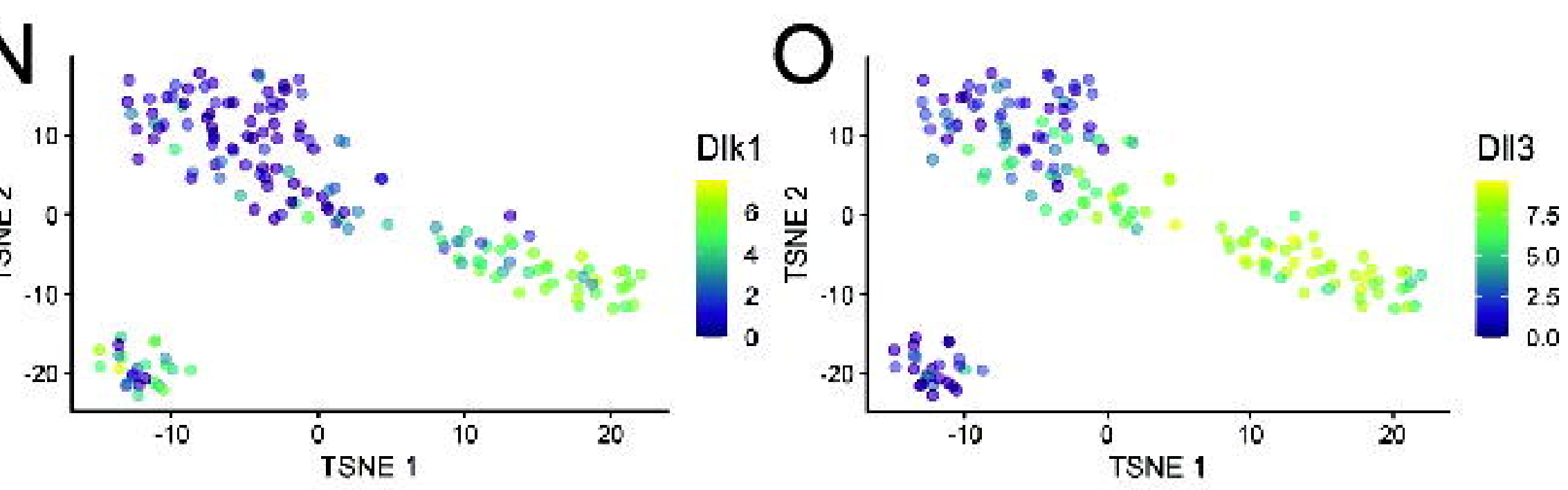

Figure 6 
